Maria Sylvia Ierardi Ribeiro

\title{
Fatores preditivos do insucesso clínico no tratamento das fístulas esofagorrespiratórias com prótese metálica autoexpansível em pacientes com câncer esofágico
}

Dissertação apresentada à Faculdade de Medicina da Universidade de São Paulo para obtenção do título de Mestre em Ciências

Programa de Ciências em Gastroenterologia

Orientador: Prof. Dr. Fauze Maluf Filho

São Paulo 
Maria Sylvia Ierardi Ribeiro

\title{
Fatores preditivos do insucesso clínico no tratamento das fístulas esofagorrespiratórias com prótese metálica autoexpansível em pacientes com câncer esofágico
}

\author{
Dissertação apresentada à Faculdade de \\ Medicina da Universidade de São Paulo para \\ obtenção do título de Mestre em Ciências \\ Programa de Ciências em Gastroenterologia \\ Orientador: Prof. Dr. Fauze Maluf Filho
}

São Paulo 
" Conheça todas as teorias, domine todas as técnicas, mas ao tocar uma alma humana, seja apenas outra alma humana" 
DEDICATÓRIA 
Aos meus amados pais Nelson e Helyette,

Exemplos de honradez, perseverança e bondade. Fontes inabaláveis de força e fé. Por nunca terem medido esforços para me oferecer ensino e instrução. Sempre presentes, me apoiando e me incentivando a realizar sonhos e a vencer obstáculos. À eles, dedico e compartilho todas as minhas conquistas.

À minhas duas irmãs Maria Fernanda e Maria Cláudia,

Por toda proteção e cuidado que dedicaram à mim, irmã mais nova. Pela nossa união, amizade inabalável e parceria em todos os momentos. Com elas, aprendi o verdadeiro significado do amor incondicional.

Ao meu marido Gerson,

Meu amor, meu melhor amigo. Por ter sido meu dedicado companheiro nesta longa caminhada, por todas alegrias, tristezas e dores compartilhadas. Por ter entendido minhas faltas, minhas ausências e não ter me deixado desanimar com as dificuldades. Juntos somos fortes.

Ao meu cunhado Ubajara,

Por ser exemplo de dedicação e amor à medicina, pela sede inesgotável do saber. Admiração por você jamais irá faltar. 
AGRADECIMENTOS 
Ao Prof. Dr. Fauze Maluf Filho, por ter realizado a orientação deste estudo de forma exímia e com o mais alto grau de profissionalismo, pelo incentivo, paciência e apoio dedicado e por todos os ensinamentos de endoscopia, ética médica e pesquisa clínica.

Ao Dr. Bruno da Costa Martins, pela participação fundamental na elaboração e execução desta pesquisa, por todas as críticas construtivas e pela grande amizade.

Ao Dr. Marcelo Simas de Lima, médico exemplar, por ter realizado o acompanhamento clínico dos pacientes envolvidos neste estudo com humanismo e grande competência.

Ao Dr. Sérgio Eiji Matuguma, por sempre transmitir seus conhecimentos teóricos e técnicos com carinho, por sua dedicação imensurável ao ensino e pelo esmero nas ilustrações desta tese. Meus sinceros agradecimentos.

À equipe do Serviço de Endoscopia Digestiva do Instituto do Câncer do Estado de São Paulo: Prof ${ }^{a}$. Dra. Adriana Vaz Safatle-Ribeiro, Dra. Carla Gusmon, Dra. Caterina Maria Pia Simioni Penncchi, Dra. Elisa Ryoka Baba, Dr. Fábio Shiguehissa Kawaguti, Dr. Felipe Alves Retes, Dr. Matheus Cavalcante Franco, Dr. Maurício Paulin Sorbello, Dr. Ricardo Sato Uemura e Dra. Stephanie Wodak Meneses, pela constante colaboração, compreensão e incentivo.

Aos Profs. Drs. Angelo Ferrari, Carlos Alberto Malheiros e Ivan Cecconello, pelas orientações valiosas fornecidas durante a qualificação desta tese.

Aos funcionários de enfermagem do Serviço de Endoscopia Digestiva do Instituto do Câncer do Estado de São Paulo, por toda a dedicação e cuidado com os pacientes.

Ao estatístico Leandro Augusto Ferreira, pela cuidadosa análise estatística e por todo auxílio na elaboração dos gráficos e tabelas deste estudo.

À Sra. Vilma Libério, secretária da pós-graduação do Programa Ciências em Gastroenterologia, pelo auxílio, gentileza e disponibilidade. 


\section{NORMATIZAÇÃO ADOTADA}

Esta tese está de acordo com as seguintes normas, em vigor no momento desta publicação:

Referências: adotado de International Committee of Medical Journals Editors (Vancouver).

Universidade de São Paulo. Faculdade de Medicina. Serviço de Biblioteca e Documentação. Guia de apresentação de dissertações, teses e monografias. Elaborado por Anneliese Carneiro da Cunha, Maria Julia de A. L. Freddi, Maria F. Crestana, Marinalva de Souza Aragão, Suely Campos Cardoso, Valéria Vilhena. $3^{\text {a }}$ Ed. São Paulo: Serviços de Biblioteca e Documentação; 2011.

Abreviaturas dos títulos dos periódicos de acordo com List of Journals Indexed in Index Medicus. 


\section{RESUMO}

Ribeiro MSI. Fatores preditivos do insucesso clinico no tratamento das fistulas esofagorrespiratórias com prótese metálica autoexpansível em pacientes com câncer esofágico [Dissertação]. São Paulo: Faculdade de Medicina, Universidade de São Paulo; 2017.

INTRODUÇÃO: A fistula esofagorrespiratória é complicação temida do câncer esofágico avançado. A paliação com prótese metálica autoexpansível é método amplamente empregado, porém com resultados conflitantes. OBJETIVO: Identificar fatores associados ao insucesso clínico do tratamento da fístula esofagorrespiratória maligna com prótese metálica autoexpansível. MÉTODOS: Estudo retrospectivo através da análise de banco de dados elaborado de forma prospectiva de pacientes submetidos ao tratamento da fístula esofagorrespiratória maligna com prótese metálica autoexpansível entre janeiro de 2009 e fevereiro de 2016 em hospital terciário dedicado ao tratamento do câncer. Foram coletados dados quanto à: características demográficas, nível de albumina sérica, capacidade funcional do paciente, doença pulmonar infecciosa em atividade no momento da passagem da prótese, tratamentos oncológicos prévios, momento do diagnóstico da fístula, tamanho e localização do trajeto fistuloso. RESULTADOS: Um total de 71 pacientes foram incluídos no estudo (55 homens, idade média de 59 anos). Insucesso clínico ocorreu em $44.3 \%$ dos pacientes. ECOG 3 ou 4, desenvolvimento da fístula durante o tratamento do câncer esofágico e diâmetro da fístula $\geq 1 \mathrm{~cm}$ foram fatores preditivos do insucesso clínico. ECOG 3 ou 4, doença pulmonar infecciosa em atividade no momento da passagem da prótese e tratamento oncológico prévio com radioterapia foram fatores preditivos de menor sobrevida. O grau de disfagia melhorou significativamente 15 dias após a passagem da prótese. A taxa total de eventos adversos foi de 30\%. Migração da prótese e a oclusão da mesma por crescimento tumoral nas extremidades da prótese foram os eventos adversos mais comumente observados. CONCLUSÃO: A prótese metálica autoexpansível é um método terapêutico efetivo para o tratamento da fístula esofagorrespiratória maligna, no entanto, ECOG 3 ou 4, desenvolvimento da fístula durante o tratamento do câncer esofágico e diâmetro da fístula $\geq 1 \mathrm{~cm}$ foram fatores preditivos do insucesso clínico após a passagem da prótese.

Descritores: neoplasias esofágicas; fístula traqueoesofágica; fístula bronquial; fístula esofágica; fístula do sistema respiratório; fístula do sistema digestório; próteses e implantes. 


\section{ABSTRACT}

Ribeiro MSI. Predictive factors of clinical failure of treatment of malignant esophageal fistula with self-expandable metallic stents [Dissertation]. São Paulo: "Faculdade de Medicina, Universidade de São Paulo", 2017.

INTRODUCTION: Malignant esophagorespiratory fistula is a serious and life-threatening complication of esophageal cancer. Self-expandable metal stents placement is a well accepted palliative treatment, however, with conflicting results. OBJECTIVE: To identify risk factors associated with clinical failure after self-expandable metal stents placement for the treatment of malignant esophagorespiratory fistula. METHODS: This was a retrospective analysis of a prospectively maintained database used at a tertiary cancer hospital, with patients treated with SEMS placement for MERF between January 2009 and February 2016. The following variables were collected: patient demographics, serum albumin level, Eastern Cooperative Oncology Group (ECOG) performance status, pulmonary infection, previous oncologic treatment, moment of diagnosis of the malignant esophagorespiratory fistula, size and classification of the fistulous tract. RESULTS: A total of 71 patients (55 males, mean age 59 years) were considered for the final analysis. Clinical failure occurred in $44.3 \%$ of the patients. ECOG 3 or 4 , fistula development during esophageal cancer treatment and fistula diameter $\geq 1 \mathrm{~cm}$ were factors associated with increased risk of clinical failure. ECOG 3 or 4, pulmonary infection at the time of SEMS placement and prior radiation therapy were predictive factors associated with lower overall survival. Dysphagia scores improved significantly 15 days after stent insertion. The overall stent-related adverse events rate was $30 \%$. Stent migration and occlusion due to tumor overgrowth were the most commonly seen adverse events. CONCLUSION: SEMS placement is a reasonable treatment option for MERF, however, ECOG 3 or 4, fistula development during esophageal cancer treatment or large fistula diameter may be independent predictors of clinical failure after stenting.

Descriptors: esophageal neoplasms; tracheoesophageal fistula; bronchial fistula; esophageal fistula; respiratory tract fistula; digestive system fistula; protheses and implants. 


\section{LISTA DE ABREVIATURAS E SIGLAS}

$\begin{array}{ll}\text { BCP } & \text { Broncopneumonia } \\ \text { CE } & \text { Câncer de esôfago } \\ \text { ECOG } & \text { Eastern Cooperative Oncology Group } \\ \text { Et al. } & \text { E outros (e colaboradores) } \\ \text { FER } & \text { Fístula esofagorrespiratória } \\ \text { HPV } & \text { Papiloma Vírus Humano } \\ \text { HC-FMUSP } & \text { Hospital das Clínicas da Faculdade de Medicina da Universidade de São } \\ & \text { Paulo } \\ \text { IC } & \text { Intervalo de Confiança } \\ \text { ICESP } & \text { Instituto do Câncer do Estado de São Paulo Octavio Frias de Oliveira } \\ \text { INCA } & \text { Instituto Nacional do Câncer } \\ \text { Nd:YAG } & \text { Neodymium-doped-yttrium-aluminum-garnet } \\ \text { OMS } & \text { Organização Mundial da Saúde } \\ \text { OR } & \text { Odds Ratio ou razão de probabilidade } \\ \text { PMAE } & \text { Prótese metálica autoexpansível } \\ \text { QT } & \text { Quimioterapia } \\ \text { RR } & \text { Risco Relativo } \\ \text { RT } & \text { Radioterapia }\end{array}$




\section{LISTA DE SÍMBOLOS}

$\begin{array}{ll}\% & \text { percentual } \\ > & \text { maior } \\ < & \text { menor } \\ \geq & \text { maior ou igual } \\ \pm & \text { mais ou menos } \\ \mathrm{cm} & \text { centímetros } \\ \mathrm{mm} & \text { milímetros } \\ \mathrm{g} / \mathrm{dL} & \text { gramas por decilitro } \\ \mathrm{Kg} / \mathrm{m}^{2} & \text { quilograma por metro quadrado } \\ v s & \text { versus }\end{array}$




\section{LISTA DE TABELAS}

TABELA 1: DADOS DEMOGRÁFICOS E PARÂMETROS CLÍNICOS DOS PACIENTES ESTUDADOS . 29

TABELA 2: PARÂMETROS ENDOSCÓPICOS E RADIOLÓGICOS DOS PACIENTES ESTUDADOS ..... 31

TABELA 3: DADOS DEMOGRÁFICOS E PARÂMETROS CLÍNICOS DOS PACIENTES QUANTO AO DESFECHO CLÍNICO

TABELA 4: PARÂMETROS ENDOSCÓPICOS E RADIOLÓGICOS DOS PACIENTES QUANTO AO DESFECHO CLÍNICO

TABELA 5: COMPARAÇÃO ENTRE OS DADOS DEMOGRÁFICOS E PARÂMETROS CLÍNICOS DOS PACIENTES QUANTO AO DESFECHO CLÍNICO

TABELA 6: DADOS DEMOGRÁFICOS E PARÂMETROS CLÍNICOS DOS PACIENTES QUANTO AOS FATORES PREDITIVOS DO INSUCESSO CLÍNICO

TABELA 7: COMPARAÇÃO ENTRE OS PARÂMETROS ENDOSCÓPICOS E RADIOLÓGICOS DOS PACIENTES QUANTO AO DESFECHO CLÍNICO

TABELA 8: PARÂMETROS ENDOSCÓPICOS E RADIOLÓGICOS DOS PACIENTES QUANTO AOS FATORES PREDITIVOS DO INSUCESSO CLÍNICO

TABELA 9: ANÁLISE DOS DADOS DEMOGRÁFICOS E PARÂMETROS CLÍNICOS DOS PACIENTES QUANTO À SOBREVIDA

TABELA 10: ANÁLISE DOS PARÂMETROS ENDOSCÓPICOS E RADIOLÓGICOS DOS PACIENTES QUANTO À SOBREVIDA

TABELA 11: EVENTOS ADVERSOS PRECOCES E TARDIOS OBSERVADOS 


\section{LISTA DE FIGURAS}

FIGURA 1 - DESENHO ESQUEMÁTICO DA FÍSTULA DO TIPO ESOFAGOTRAQUEAL ...................... 4

FIGURA 2 - DESENHO ESQUEMÁTICO DA FÍSTULA DO TIPO ESOFAGOBRÔNQUICA .................... 5

FIGURA 3 - DESENHO ESQUEMÁTICO DA FÍSTULA DO TIPO ESOFAGOPULMONAR ...................... 6

FIGURA 4 - A: VISÃO ENDOSCÓPICA DA FÍSTULA ESOFÁGICA (SETA); B: VISÃO ENDOSCÓPICA DA PRÓTESE METÁLICA EXPANDIDA EM ESÔFAGO; C: INJEÇÃO DE MEIO DE CONTRASTE CONFIRMANDO A OCLUSÃO DA FÍSTULA PELA PRÓTESE (IMAGEM RADIOLÓGICA).................. 19

FIGURA 5 - VISÃO ENDOSCÓPICA DE EVENTOS ADVERSOS DAS PRÓTESES METÁLICAS: A:

FÍSTULA ESOFÁGICA (SETA); B: OBSTRUÇÃO DA PRÓTESE POR CRESCIMENTO TUMORAL NA EXTREMIDADE PROXIMAL DA PRÓTESE; C: MIGRAÇÃO DISTAL DA PRÓTESE PARA O ESTÔMAGO.

FigURA 6 - FLUXOGRAMA DOS PACIENTES INCLUÍDOS NO ESTUDO 


\section{LISTA DE GRÁFICOS}

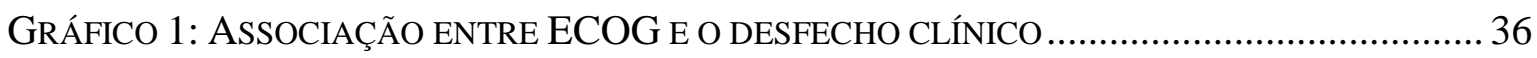

GRÁFICO 2: ASSOCIAÇÃO ENTRE DIÂMETRO DA FÍSTULA E O DESFECHO CLÍNICO.................. 40

GRÁFICO 3: DISTRIBUIÇÃO DOS PACIENTES EM RELAÇÃO AO GRAU DE DISFAGIA ANTES DA PMAE

GRÁFICO 4: DistRIBUIÇÃO DOS PACIENTES EM RELAÇÃO AO GRAU DE DISFAGIA 15 DIAS APÓS A PMAE. 43

GRÁFICO 5: COMPARAÇÃO ENTRE OS GRAUS DE DISFAGIA ANTES E APÓS A PMAE 44

GRÁFICO 6: SOBREVIDA DOS PACIENTES QUANTO OS GRUPOS DE SUCESSO E INSUCESSO CLÍNICO

GRÁFICO 7: SOBREVIDA QUANTO AO ECOG 46

GRÁFICO 8: SOBREVIDA QUANTO À PRESENÇA DE DOENÇA PULMONAR INFECCIOSA EM ATIVIDADE

GRÁFICO 9: SOBREVIDA QUANTO AO TIPO DE TRATAMENTO ONCOLÓGICO PRÉVIO .48 


\section{SUMÁRIO}

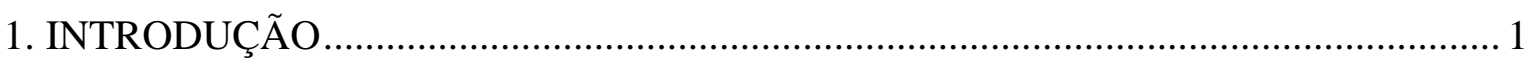

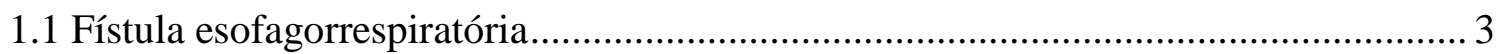

1.2 Histórico do tratamento da fístula esofagorrespiratória.......................................... 7

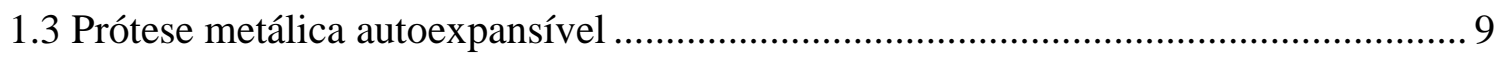

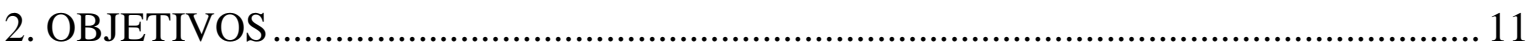

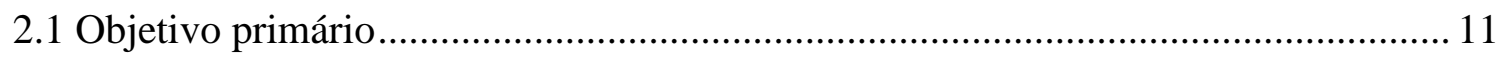

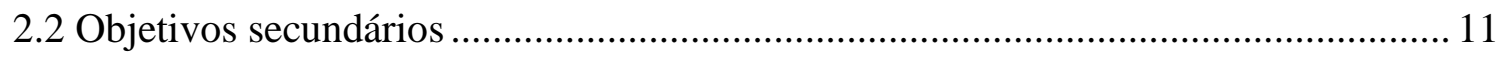

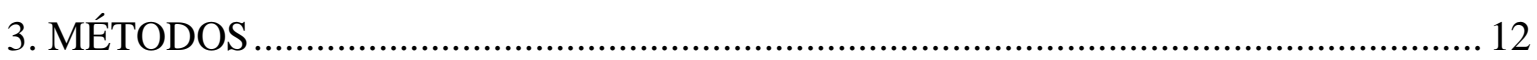

3.1 Critérios de inclusão e exclusão....................................................................... 12

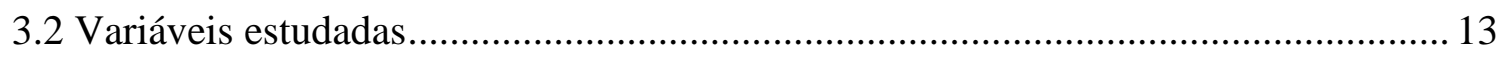

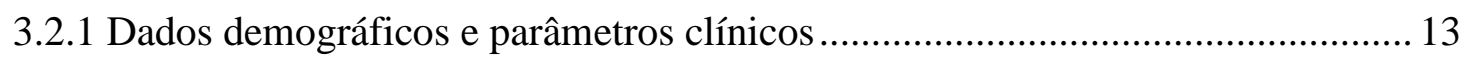

3.2.2 Parâmetros endoscópicos e radiológicos ......................................................... 16

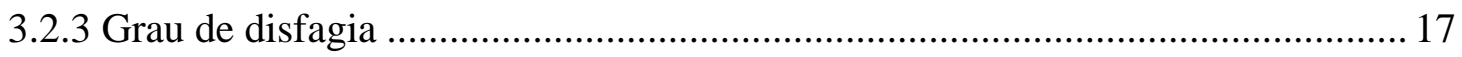

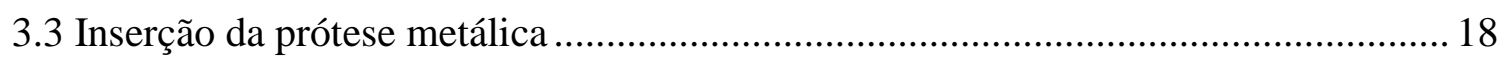

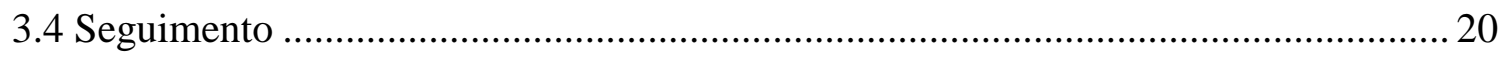

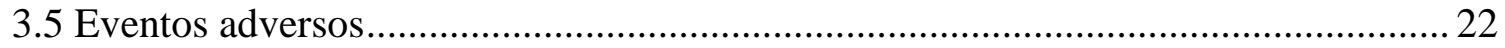

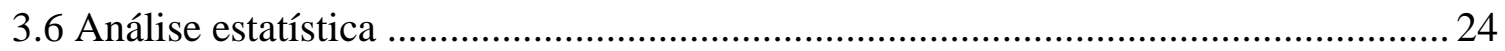

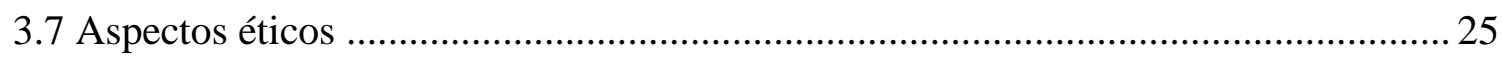




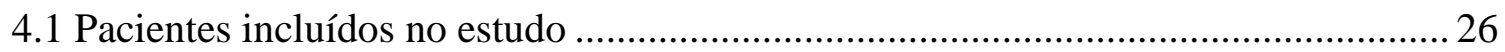

4.2 Dados demográficos e parâmetros clínicos ........................................................... 28

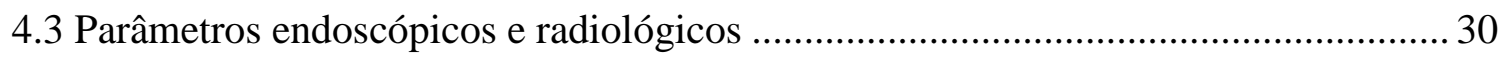

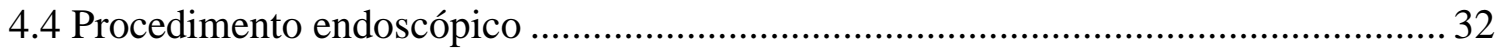

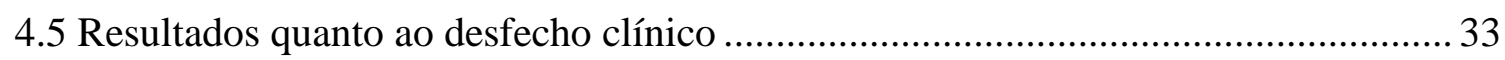

4.5.1 Análise dos dados demográficos e parâmetros clínicos quanto ao desfecho

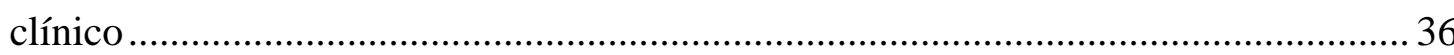

4.5.2 Análise dos parâmetros endoscópicos e radiológicos quanto ao desfecho clínico

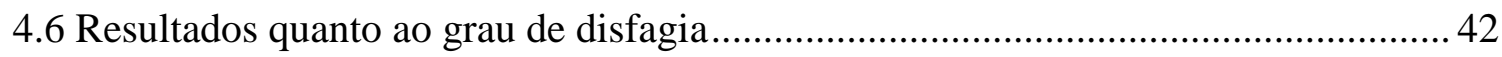

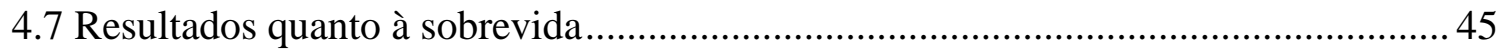

4.7.1 Análise dos dados demográficos e parâmetros clínicos quanto à sobrevida ....... 46

4.7.2 Análise dos parâmetros endoscópicos e radiológicos quanto à sobrevida ...........50

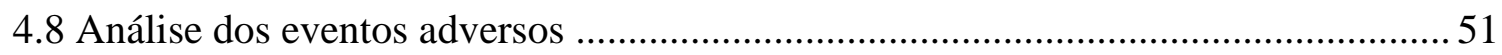

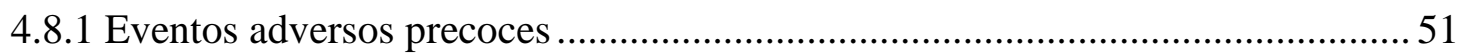

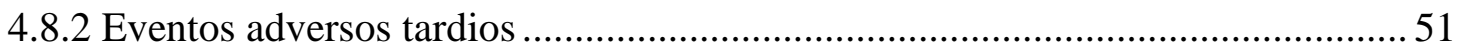

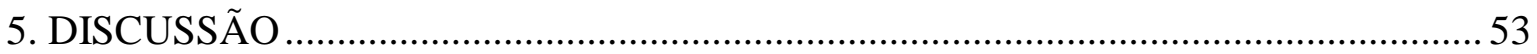

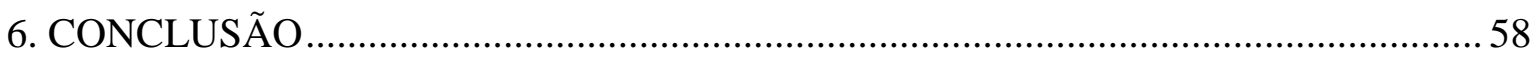

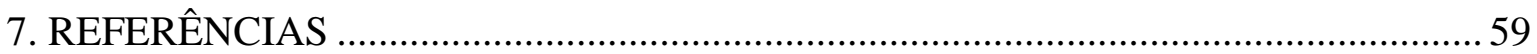




\section{INTRODUÇÃO}

O câncer de esôfago (CE) é a oitava neoplasia maligna mais frequente em todo o mundo, ocupando também a sexta posição em causa de mortes entre todos os tipos de câncer. ${ }^{1}$ Nos Estados Unidos, o CE corresponde a $1 \%$ de todos os tumores, com estimativa de 16.940 novos casos e 15.690 mortes em 2017, alcançando o sétimo lugar em causa de mortes por câncer entre as pessoas do sexo masculino. ${ }^{2}$ No Brasil, de acordo com dados do Instituto Nacional de Câncer (INCA), o CE está entre as dez neoplasias mais incidentes, sendo a sexta neoplasia mais frequente entre pessoas do sexo masculino e a décima terceira entre as do sexo feminino. Somente no ano de 2013, o número de óbitos somou 7.930 casos. Estima-se que a incidência no ano de 2016 tenha sido de 10.810 novos casos. ${ }^{3}$

Os dois tipos histológicos principais do CE são o carcinoma epidermóide escamoso e o adenocarcinoma. Em nosso meio, o carcinoma epidermóide escamoso representa cerca de $96 \%$ das neoplasias esofágicas diagnosticadas. No entanto, a incidência do adenocarcinoma vem aumentando progressivamente. ${ }^{3}$

A etiologia do CE não está completamente esclarecida, no entanto, reconhecem-se vários fatores de risco associados ao desenvolvimento da doença. Entre eles, destacam-se: idade avançada, história familiar de CE, abuso crônico de tabaco e álcool, antecedente pessoal de carcinoma espinocelular de cabeça e pescoço, infecção pelo papiloma vírus humano (HPV), acalasia, consumo frequente de bebidas quentes e alimentos ricos em nitrosaminas e aflotoxinas, deficiência de riboflavina e vitamina A, esôfago de Barrett, lesões cáusticas prévias, tilose e a síndrome de Plummer-Vinson. ${ }^{4}$

O diagnóstico definitivo do CE se dá através do exame de endoscopia digestiva alta com obtenção de biópsias da lesão e muito frequentemente é realizado já em fase avançada da doença, após o aparecimento dos primeiros sintomas disfágicos. ${ }^{5}$

Recentes avanços terapêuticos nas áreas oncológica e cirúrgica aumentaram a possibilidade de cura do CE. Com o desenvolvimento e aprimoramento da esofagectomia minimamente invasiva na última década, tornou-se possível obtenção de melhores resultados cirúrgicos, associados a menores índices de complicações. Recentemente, Sallum et al. $^{6}$, avaliou resultados de pacientes submetidos à esofagectomia com 
linfadenectomia por videotoracoscopia para o tratamento do CE no Hospital das Clínicas da Faculdade de Medicina da Universidade de São Paulo. Neste estudo, destacam-se a baixa morbimortalidade e elevada sobrevivência tardia, que atingiu 69\% (IC 95\%, 57\% $83 \%)$ em cinco anos.

Por outro lado, cerca de $50 \%$ dos pacientes apresentam doença locorregional avançada ou metastática ao momento do diagnóstico, com grave comprometimento nutricional e queda do estado geral, reduzindo a possibilidade de um tratamento curativo. ${ }^{7-}$ ${ }^{9}$ Nestes, a paliação dos sintomas e o manejo das complicações ainda é a melhor opção.

A paliação por via endoscópica é amplamente utilizada e visa principalmente ao retorno da ingesta alimentar e à melhora nutricional do paciente. Entre os métodos endoscópicos disponíveis para restaurar a patência esofágica e, consequentemente, aliviar os sintomas disfágicos, destacam-se as sondas e os balões dilatadores, o laser Neodymiumyttrium-aluminum-garnet (Nd:YAG), as injeções com álcool absoluto e com quimioterápicos, a terapia fotodinâmica, a coagulação com plasma de argônio, a eletrocoagulação bipolar e as próteses esofágicas. ${ }^{10,11}$ Esses métodos podem ser usados tanto isoladamente como em associação, apresentando resultados variáveis quanto ao grau de alívio da disfagia e quanto ao período de recorrência dos sintomas.

Segundo revisão sistemática elaborada pela colaboração Cochrane, a colocação de prótese metálica autoexpansível (PMAE) é o método mais rápido e eficaz de paliação da disfagia no CE, seguido pela braquiterapia intraluminal em altas doses. Ambas as terapias se mostraram seguras e com necessidade de poucas reintervenções.

Em estudo realizado por De Moura et al. ${ }^{12}$, no Hospital das Clínicas da Universidade de São Paulo, 40 pacientes com câncer esofágico avançado foram submetidos a tratamento paliativo, ou por bypass esofágico (grupo cirúrgico) ou por PMAE (grupo endoscópico), sendo observado que tanto a permanência hospitalar quanto o custo da internação foram significativamente maiores no grupo cirúrgico (15,5 dias vs 3 dias, $p<0,001$; US\$ 4.690,45 $\pm 1.360,28 v s$ US\$ 2.618,24 $\pm 944,98, p<0,001$ ). 


\subsection{Fístula esofagorrespiratória}

A fístula esofagorrespiratória (FER) é a temida complicação do câncer de esôfago. É definida como uma comunicação patológica entre o esôfago e a árvore respiratória, estando presente entre 5 a $15 \%$ dos indivíduos com neoplasia esofágica e em menos de $1 \%$ dos indivíduos com carcinoma broncogênico. ${ }^{13,14}$ Sua incidência apresentou considerável aumento nos últimos 30 anos, comprometendo significativamente a qualidade de vida dos pacientes e, na ausência de tratamento adequado, a sobrevida usualmente se restringe a menos de seis semanas. ${ }^{15}$

A FER pode ser classificada em quatro tipos, conforme o segmento envolvido da árvore respiratória. As mais frequentes são as fístulas entre o esôfago e a traqueia, denominadas esofagotraqueais (Figura 1), observadas em 52\% a 57\% dos casos. Quando a comunicação ocorre entre o esôfago e um dos brônquios, são chamadas de esofagobrônquicas (Figura 2), ocorrendo em 37\% a $40 \%$ dos casos. No restante dos pacientes (3\% a 11\%), a comunicação é estabelecida perifericamente com o parênquima pulmonar e com a pleura, formando as fístulas esofagopulmonares e as esofagopleurais (Figura 3). ${ }^{16}$

Quanto à etiologia, a FER pode ser causada por invasão direta tumoral, provocada por tratamentos como a radioterapia e quimioterapia, e até mesmo ser ocasionada pelo uso de próteses esofágicas ou traqueais que causam compressão excessiva e posterior necrose da parede esofágica consequente à isquemia local. ${ }^{17,18}$

Os sintomas típicos do paciente portador de FER são quadros de tosse associados à ingesta alimentar e pneumonias aspirativas de repetição, presentes em até $95 \%$ dos casos. ${ }^{19}$

O diagnóstico da FER nem sempre é fácil de ser feito, sendo especialmente desafiador no caso de pequenas fístulas, o que requer elevada suspeição clínica e equipe médica experiente. Os exames de endoscopia digestiva alta e broncoscopia são úteis quando há visualização direta do orifício fistuloso, através do qual muitas vezes é possível notar passagem de saliva e alimentos para o interior da via respiratória, além da passagem de ar e secreção respiratória para o esôfago. Quando não é possível a visualização direta da fístula, o esofagograma pode ser solicitado e deve ser feito de forma cautelosa, com o uso 
de meio de contraste hidrossolúvel, sendo diagnóstico se houver extravasamento do mesmo para a árvore respiratória. A tomografia computadorizada de tórax é útil não apenas para o diagnóstico, mas também para a avaliação do quadro pulmonar e da extensão da neoplasia e sua relação com as estruturas adjacentes. ${ }^{20}$

Em média, a fístula se desenvolve cerca de oito meses após o diagnóstico do CE e, uma vez estabelecida sua presença, o tratamento deve ser prontamente instituído para evitar a contaminação contínua da via aérea e o óbito por sepse de foco pulmonar. ${ }^{21,22}$ Desta forma, o fechamento da FER e o restabelecimento da capacidade de ingesta alimentar por via oral são considerados tão importantes quanto o tratamento da doença subjacente.

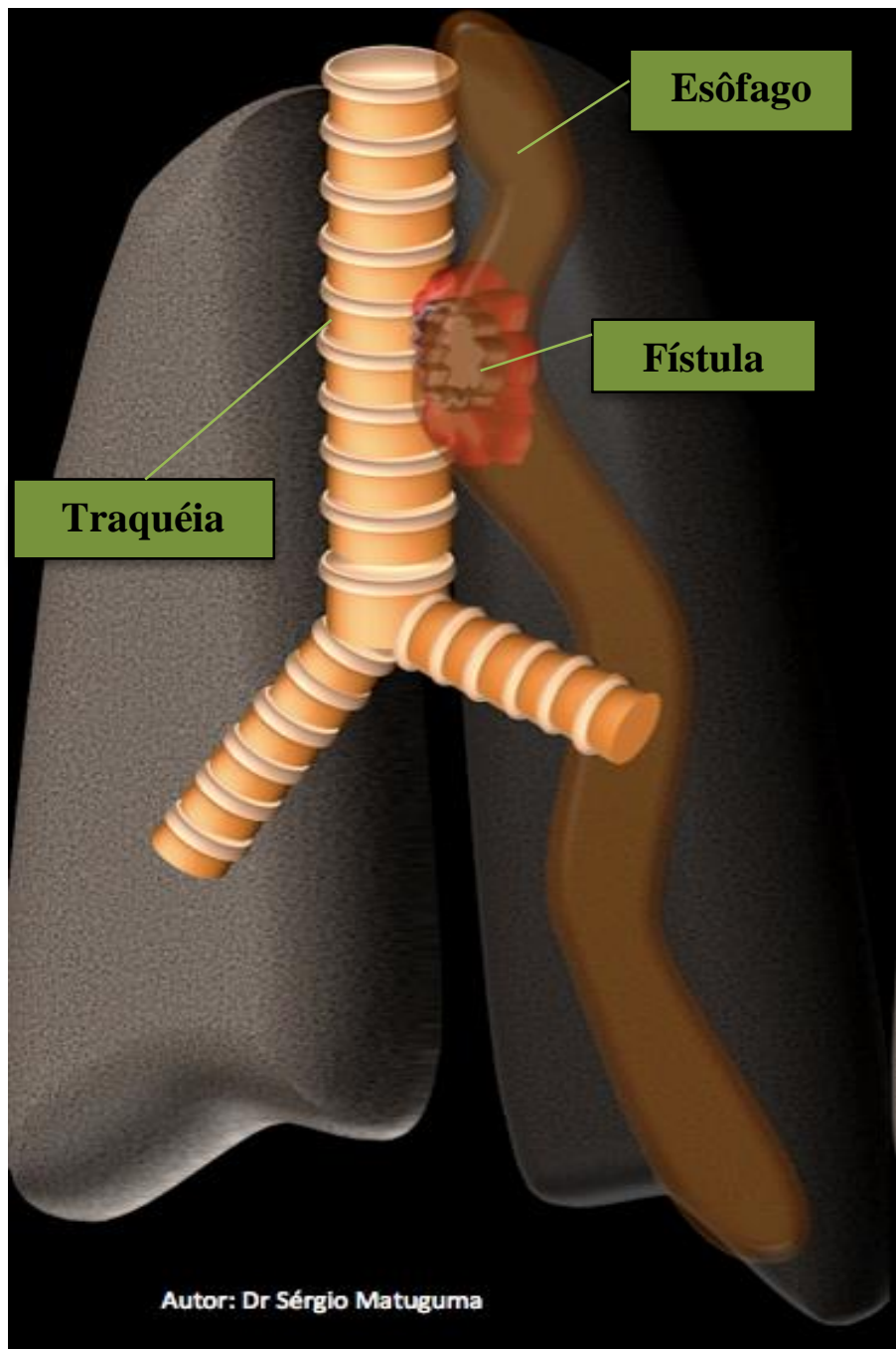

FIGURA 1 - DESENHO ESQUEMÁTICO DA FÍSTULA DO TIPO ESOFAGOTRAQUEAL 


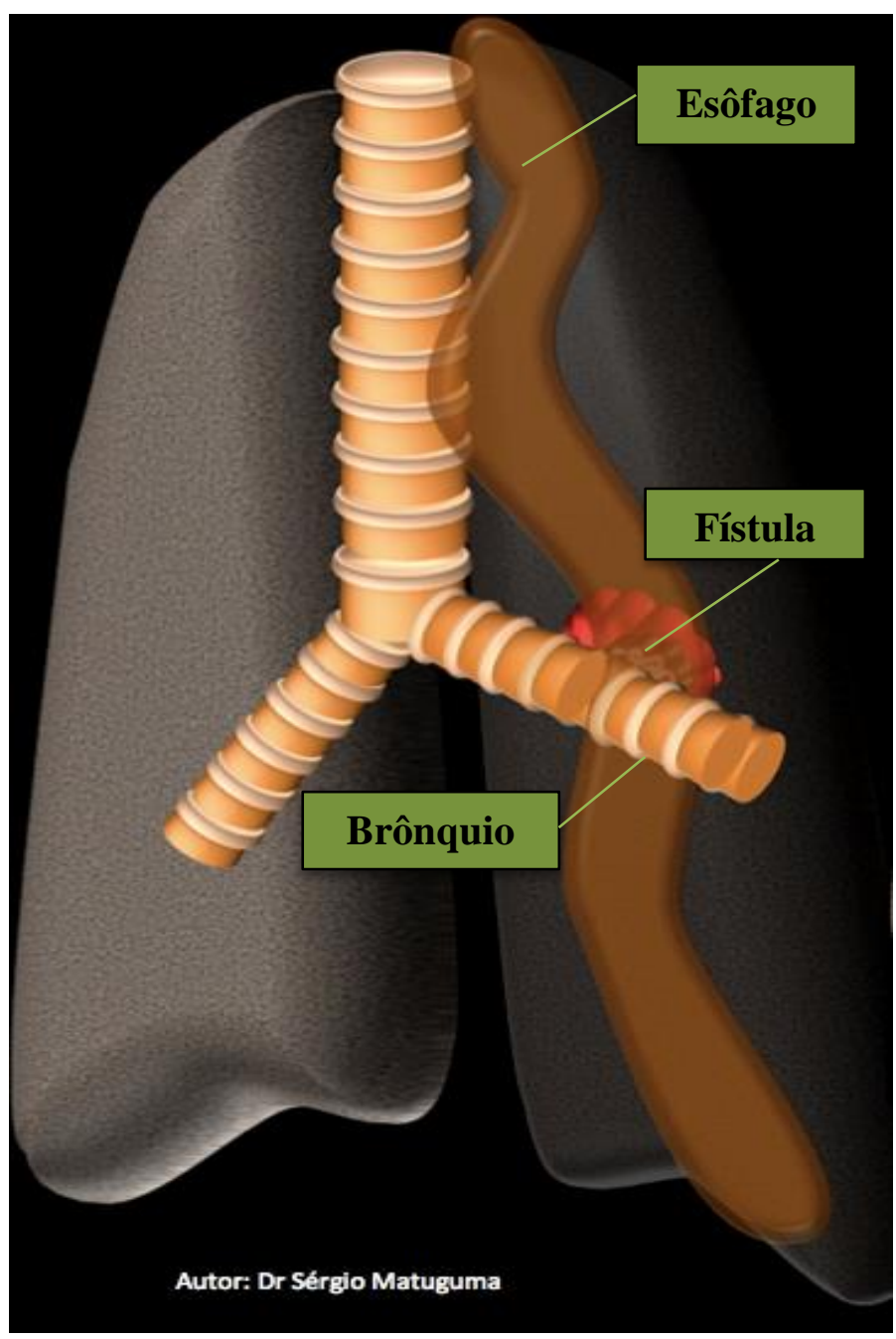

FigURA 2 - DESENHO ESQUEMÁTICO DA FÍSTULA DO TIPO ESOFAGOBRÔNQUICA 


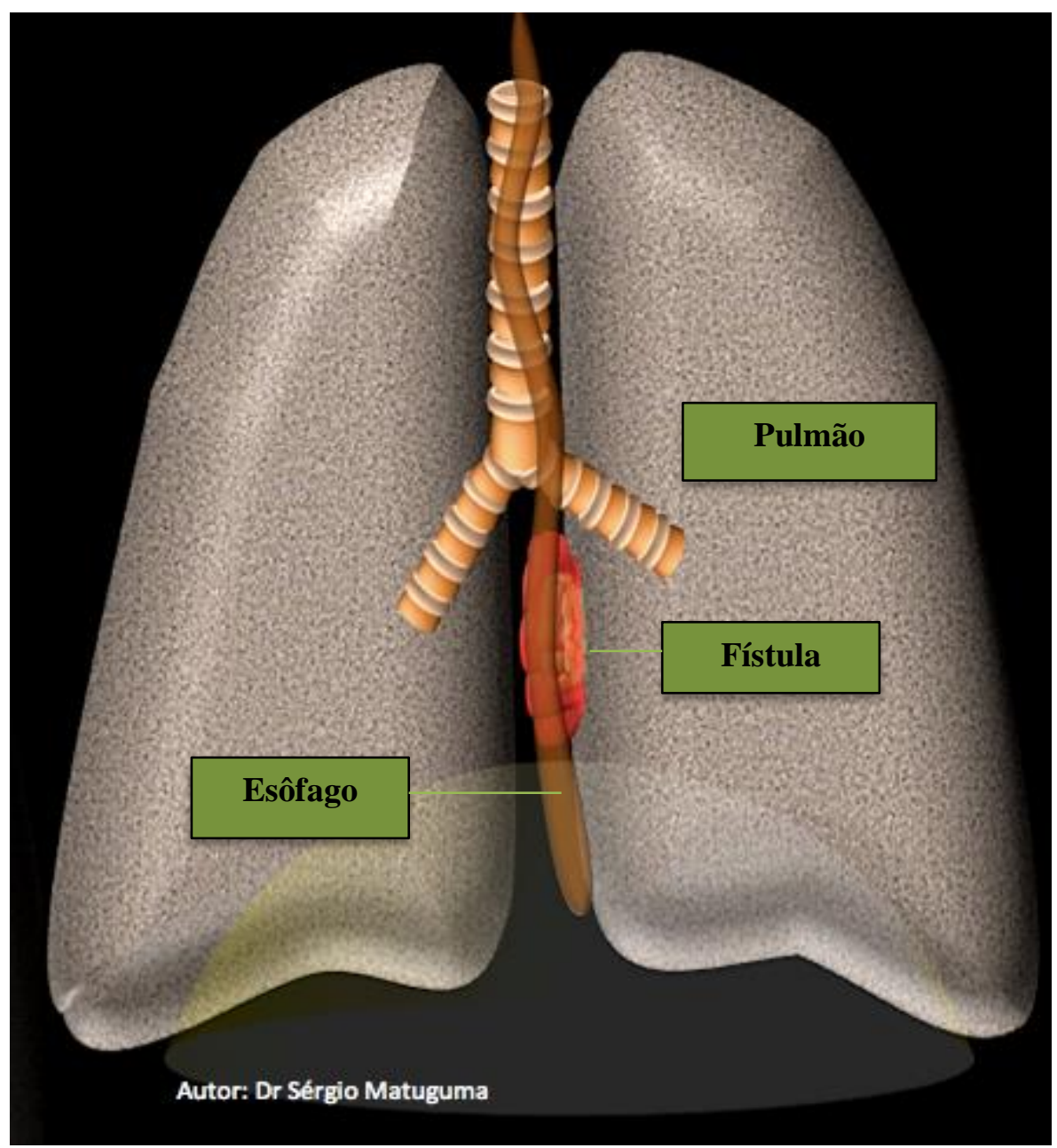

FigURA 3 - DESENHO ESQUEMÁTICO DA FÍSTULA DO TIPO ESOFAGOPULMONAR 


\subsection{Histórico do tratamento da fístula esofagorrespiratória}

No passado, as FER podiam ser tratadas cirurgicamente nos pacientes que possuíam condições clínicas favoráveis para o ato cirúrgico ou eram manejadas conservadoramente, através da instituição de nutrição parenteral total aliada ao uso de antibióticos de largo espectro nos pacientes mais debilitados.

No entanto, ambos os tratamentos eram associados às altas taxas de morbimortalidade (15\% a 40\%), além de demandarem tempo de internação prolongado em centros de terapia intensiva, gerando altos custos hospitalares. ${ }^{21}$ De fato, Davydov et al. ${ }^{23}$, analisaram 35 pacientes, diagnosticados com fístulas esofágicas malignas, que foram submetidos a diversas modalidades de tratamentos cirúrgicos, tal qual a esofagectomia subtotal de Ivor Lewis e o bypass esofágico, observando taxas de complicação de $40 \%$ e de mortalidade imediata de $14,3 \%$, a despeito de uma sobrevida média prolongada (13 meses).

Nos anos 80, o uso de próteses plásticas não expansíveis inseridas por via endoscópica foi considerado o tratamento de escolha para o manejo das FER, sendo uma alternativa terapêutica minimamente invasiva e revolucionária. Elevadas taxas de sucesso técnico inicial, tanto de inserção quanto de oclusão da fístula foram descritas na literatura como sendo de até $90 \%{ }^{21}$ No entanto, complicações como perfuração esofágica, hemorragia, necrose tecidual por pressão, obstrução e migração da prótese ocorriam em aproximadamente $15 \%$ a $40 \%$ dos pacientes, limitando a disseminação do método, apesar de seu baixo custo quando comparado aos outros métodos disponíveis. ${ }^{17}$ Nesta época, Domene et $a^{24} .^{24}$ realizaram um estudo no Hospital das Clínicas da Universidade de São Paulo no qual 15 pacientes portadores de fístula esofagorrespiratória maligna foram submetidos à tunelização endoscópica com tubo plástico semi-rígido, obtendo $80 \%$ de sucesso na oclusão da fístula e $36,6 \%$ de complicações imediatas e tardias, com tempo médio de internação de 7,3 dias.

Na década de 90 , Song et al. ${ }^{25}$, relataram o uso de próteses expansíveis recobertas com silicone, descrevendo menores taxas de morbidade e de mortalidade quando comparadas a outras modalidades paliativas existentes. Em seguida, diferentes tipos de próteses foram desenvolvidas e utilizadas. 
Coube a Domschke et al. ${ }^{26}$, em 1990, descrever a primeira inserção bem sucedida de uma PMAE em pacientes com neoplasia esofágica avançada. $\mathrm{Na}$ época, seu uso para o tratamento da FER mostrou sucesso técnico variável (64\% a 100\%), com sobrevida média entre 42 e 59 dias. $^{27}$ Desde então, seu emprego vem sendo cada vez mais difundido e representa atualmente importante ferramenta no manejo da FER, graças a sua eficácia, segurança e facilidade de inserção quando comparada à prótese plástica. ${ }^{28,29}$ Soma-se a isso o fato destas próteses estarem disponíveis nos hospitais dedicados ao tratamento do paciente oncológico. 


\subsection{Prótese metálica autoexpansível}

Atualmente as PMAEs são fabricadas com nitinol, liga metálica de níquel e titânio, e podem ser de três tipos, de acordo com sua cobertura: parcialmente recoberta, totalmente recoberta e não recoberta, sendo as duas primeiras usadas preferencialmente para o tratamento da fístula maligna com o intuito de prevenir invasão tumoral entre as malhas da prótese e recobrir completamente o orifício fistuloso.

A taxa de sucesso no fechamento da fístula com PMAE varia entre $70 \%$ a $100 \%$ e pode promover melhora instantânea da disfagia através da restauração da patência esofágica, evitando alimentação pelo uso de sonda nasoenteral ou por gastrostomia percutânea, além de melhorar a qualidade de vida e reduzir o número de intervenções adicionais. ${ }^{16,30,31}$

Shin et al. ${ }^{32}$, realizaram um estudo com seguimento a longo prazo de 61 pacientes com fístula esofagorrespiratória submetidos ao tratamento paliativo através do uso de próteses metálicas expansíveis recobertas. A taxa de sucesso clínico foi de $80 \%$, com média de sobrevida de 93,8 dias (13,4 semanas). Outro estudo desenvolvido retrospectivamente por Balazs et al. ${ }^{19}$ envolvendo 264 pacientes, demonstrou que o fechamento da fístula pela PMAE promoveu melhora significativa da sobrevida quando comparado a pacientes que receberam suporte nutricional por gastro/jejunostomia ou apenas suporte intensivo (3,4 vs 1,1 vs 1,3 meses, $p<0,001)$.

Alguns estudos compararam os diversos tratamentos disponíveis, tais como próteses traqueais, próteses plásticas esofágicas e aplicação de agentes adesivos biológicos diretamente no trajeto fistuloso, com vantagens para as próteses metálicas autoexpansíveis. ${ }^{3}$ Herth et al. ${ }^{33}$, comparam as taxas de sobrevida de pacientes com FER tratados através da colocação de PMAE esofágica e prótese em via aérea ou combinação de ambas as próteses. A taxa de sobrevida foi significativamente maior no grupo de pacientes que receberam PMAE esofágica, em detrimento dos grupos com prótese em via aérea ou dupla prótese (262,8 dias vs 219,1 dias vs 252,9 dias, $p=0,023)$. Chen et al. ${ }^{34}$, compararam utilização de prótese esofágica e alimentação por gastro/jejunostomia para a paliação da fístula traqueoesofágica e observaram que pacientes que foram submetidos à inserção da 
PMAE apresentaram aumento global da sobrevida (125 dias vs 55 dias, $p=0,007$ ), possivelmente pelo melhor controle da infecção respiratória.

Contudo, reconhece-se que existem eventos adversos relacionados à PMAE impactando negativamente a sobrevida destes pacientes. A taxa de mortalidade relacionada ao procedimento pode chegar a 3\%. ${ }^{35}$ Também não está claro se o fechamento da fístula com PMAE em pacientes com doença pulmonar pré-existente, como pneumonia e abscesso pulmonar, pode diminuir o tempo de sobrevida pela oclusão do sítio de drenagem das secreções para o esôfago, exacerbando o quadro infeccioso.

Até o momento existem na literatura poucos trabalhos dedicados à análise e estudo destas questões acima mencionadas, principalmente com acompanhamento por período superior a 120 dias. A maioria das publicações referem-se a pequenos estudos de coorte, com índices variáveis de sucesso e eventos adversos. ${ }^{36-40}$

Estes fatos justificaram a avaliação do uso de prótese metálica autoexpansível no tratamento endoscópico do câncer esofágico com fístula esofagorrespiratória realizado em hospital de atenção terciária à saúde, visando, assim, a identificar fatores preditivos do insucesso clínico após a passagem da PMAE. 


\section{OBJETIVOS}

\subsection{Objetivo primário}

Identificar fatores clínicos, radiológicos e endoscópicos associados ao insucesso clínico do tratamento paliativo da fístula esofagorrespiratória com prótese metálica autoexpansível em pacientes com neoplasia esofágica avançada.

\subsection{Objetivos secundários}

Identificar fatores que impactaram negativamente a sobrevida dos pacientes submetidos à passagem de PMAE para o tratamento paliativo da fístula esofagorrespiratória maligna.

Identificar possíveis eventos adversos relacionados ao uso da prótese metálica autoexpansível.

Descrever o efeito da inserção da PMAE no grau de disfagia referido pelos pacientes. 


\section{MÉTODOS}

Trata-se de estudo retrospectivo realizado através da análise de banco de dados elaborado de forma prospectiva, englobando pacientes portadores de neoplasia esofágica avançada que foram submetidos ao tratamento endoscópico da fístula esofagorrespiratória pela passagem de prótese metálica autoexpansível, entre janeiro de 2009 e fevereiro de 2016, no Instituto do Câncer do Estado de São Paulo Octavio Frias de Oliveira, do Hospital das Clínicas da Faculdade de Medicina da Universidade de São Paulo (ICESP, HC-FMUSP). Ressalta-se que a indicação da PMAE foi fruto de avaliação multidisciplinar.

\subsection{Critérios de inclusão e exclusão}

Os critérios de inclusão foram:

- Portadores de neoplasia esofágica maligna confirmada histologicamente;

- Idade acima de 18 anos;

- Portadores de fístula esofagorrespitarória submetidos à passagem de PMAE.

Os critérios de exclusão foram:

- Manipulação cirúrgica esofágica prévia;

- Fístula decorrente de neoplasia extraesofágica;

- Perda do seguimento inferior a 15 dias;

- Características clínicas, radiológicas e/ou endoscópicas incompletas no banco de dados do paciente. 


\subsection{Variáveis estudadas}

\subsubsection{Dados demográficos e parâmetros clínicos}

Os seguintes parâmetros clínicos e demográficos foram extraídos do banco de dados dos pacientes:

- Sexo:

Os pacientes foram alocados segundo o sexo masculino ou feminino.

- Idade:

Os pacientes foram divididos em grupos com idade menor que 60 anos e maior ou igual a 60 anos no momento da passagem da PMAE.

- Albumina sérica:

A classificação utilizada foi aquela definida pelo Guia Prático Avançado de Nutrição e Feridas, em $2006^{41}$ :

○ Normal: $>3,5 \mathrm{~g} / \mathrm{L}$

○ Depleção leve: $2,8-3,5 \mathrm{~g} / \mathrm{L}$

○ Depleção moderada: $2,1-2,7 \mathrm{~g} / \mathrm{L}$

○ Depleção intensa: $<2,1 \mathrm{~g} / \mathrm{L}$

Os pacientes foram divididos em dois grupos, aqueles com albumina sérica normal ou portadores de depleção leve e aqueles com depleção moderada ou grave de albumina no momento da passagem da PMAE.

- Capacidade Funcional:

Os pacientes foram classificados segundo a medida global do desempenho funcional pela escala Eastern Cooperative Oncology Group (ECOG) Performance Status ${ }^{42}$ em: 
○ ECOG 0: completamente ativo e capaz de realizar sem restrições todas as atividades que realizava antes da doença;

- ECOG 1: realiza atividades fisicamente extenuantes com restrições, porém deambulante e capaz de realizar tarefas leves ou de natureza sedentária;

○ ECOG 2: deambulante por mais de $50 \%$ das horas em vigília e capaz de cuidar de si mesmo, porém incapaz de realizar atividades profissionais;

- ECOG 3: capacidade limitada a apenas cuidar de si mesmo, acamado ou sentado por mais de $50 \%$ das horas em vigília;

○ ECOG 4: completamente incapaz, não consegue cuidar de si mesmo, acamado ou sentado todo o tempo;

○ ECOG 5: óbito.

Os pacientes foram alocados em dois grupos, aqueles com ECOG 0,1 ou 2 e aqueles com ECOG 3 ou 4.

- Presença ou ausência de doença pulmonar no momento da inserção da PMAE:

Foram extraídos dos prontuários os resultados dos exames radiológicos realizados para a avaliação pulmonar dos pacientes. Considerou-se doença pulmonar decorrente de fístula esofagorrespiratória, o paciente que apresentou achados radiológicos e clínicos de broncopneumonia ou abscesso pulmonar no momento da passagem da PMAE.

Definiu-se abscesso pulmonar como a coleção infectada localizada no parênquima pulmonar, formando cavidades, diagnosticada através de exame tomográfico.

- Momento do diagnóstico da fístula esofagorrespiratória:

Os pacientes foram alocados em dois grupos, aqueles que apresentaram a FER já ao diagnóstico da neoplasia esofágica e aqueles que desenvolveram a FER durante o tratamento do câncer esofágico. 
- Tratamentos oncológicos prévios realizados:

Os pacientes foram divididos em dois grupos, aqueles que eram virgens de tratamento oncológico ou apenas haviam sido submetidos à quimioterapia e outro grupo formado por aqueles que haviam sido submetidos à radioterapia associada ou não à quimioterapia. 


\subsubsection{Parâmetros endoscópicos e radiológicos}

Os seguintes parâmetros endoscópicos e radiológicos foram extraídos do banco de dados dos pacientes:

- Diâmetro da fístula:

Para definir o diâmetro da fístula foram feitas medidas utilizando-se uma pinça de biópsia convencional aberta como referência $(9 \mathrm{~mm}$, Radial Jaw, Boston Scientific, Marlborough MA, USA) através de endoscopia digestiva alta realizada previamente à passagem da prótese. Os pacientes foram então agrupados em portadores de fístula com diâmetro menor que $1 \mathrm{~cm}$ e portadores de fístula com diâmetro maior ou igual a $1 \mathrm{~cm}$.

- Localização anatômica da fístula:

Foram utilizados os laudos dos exames de tomografia computadorizada de tórax e de broncoscopia para definir a localização anatômica das fístulas. Dividiu-se os pacientes em dois grupos, aqueles com fístulas do tipo esofagotraqueal ou esofagobrônquica e aqueles com fistulas esofagopleural ou esofagopulmonar. 


\subsubsection{Grau de disfagia}

Para quantificar o grau de disfagia foi utilizada a classificação de Mellow e Pinkas ${ }^{43}$ :

○ Grau 0: ausência de disfagia;

○ Grau 1: disfagia para alimentos sólidos;

- Grau 2: disfagia para alimentos pastosos;

- Grau 3: disfagia para líquidos;

○ Grau 4: paciente afágico.

Pacientes em uso de sonda nasoenteral, gastrostomia ou jejunostomia foram considerados como afágicos (Grau 4). 


\subsection{Inserção da prótese metálica}

Todos os procedimentos foram realizados no Serviço de Endoscopia do ICESP. Os pacientes foram posicionados em decúbito dorsal, submetidos a anestesia geral ou sedação consciente, dependendo da avaliação do anestesiologista.

A exata localização e extensão do tumor, bem como a localização da fístula esofagorrespiratória já haviam sido estudadas em exame endoscópio prévio.

A depender da avaliação do endoscopista, o endoscópio de fino calibre $(4,9 \mathrm{~mm}$, Olympus Medical, Tokyo, Japan) foi empregado com o intuito de permitir a adequada avaliação do lúmen esofágico, gástrico e duodenal.

Definida a fístula, procedeu-se à demarcação dos limites superior e inferior da lesão, com utilização de marcadores externos metálicos ou internamente, por injeção submucosa de meio de contraste lipossolúvel.

Com auxílio de fluoroscopia ou visualização direta, foi posicionado o fio guia hidrofílico (0,035-inch Jagwire, Boston Scientific) em posição gástrica. Após a retirada do endoscópio, a prótese foi introduzida por sobre o fio guia e liberada na posição planejada por controle radioscópico ou sob visão direta.

As próteses utilizadas foram de fabricantes variados, sendo selecionada a mais adequada para cada caso conforme as características do tumor e avaliação prévia da equipe (Boston Scientific, Wilson Cook, MI Tech, SolcoIntermed), com diâmetros variando entre $18 \mathrm{~mm}$ e $23 \mathrm{~mm}$ e comprimentos entre $8 \mathrm{~cm}$ e $15 \mathrm{~cm}$, sendo que, necessariamente, a prótese escolhida possuía de $2 \mathrm{~cm}$ a $4 \mathrm{~cm}$ a mais do que a extensão da neoplasia.

Ao final do procedimento, exame radiológico com utilização de meio de contraste hidrossolúvel foi realizado para confirmar a oclusão imediata da fístula.

$\mathrm{Na}$ figura 4, pode-se observar a visão endoscópica da fístula e da prótese no esôfago após sua liberação, além do exame radiológico com utilização de meio de contraste que confirmou a oclusão completa da fístula pela prótese. 


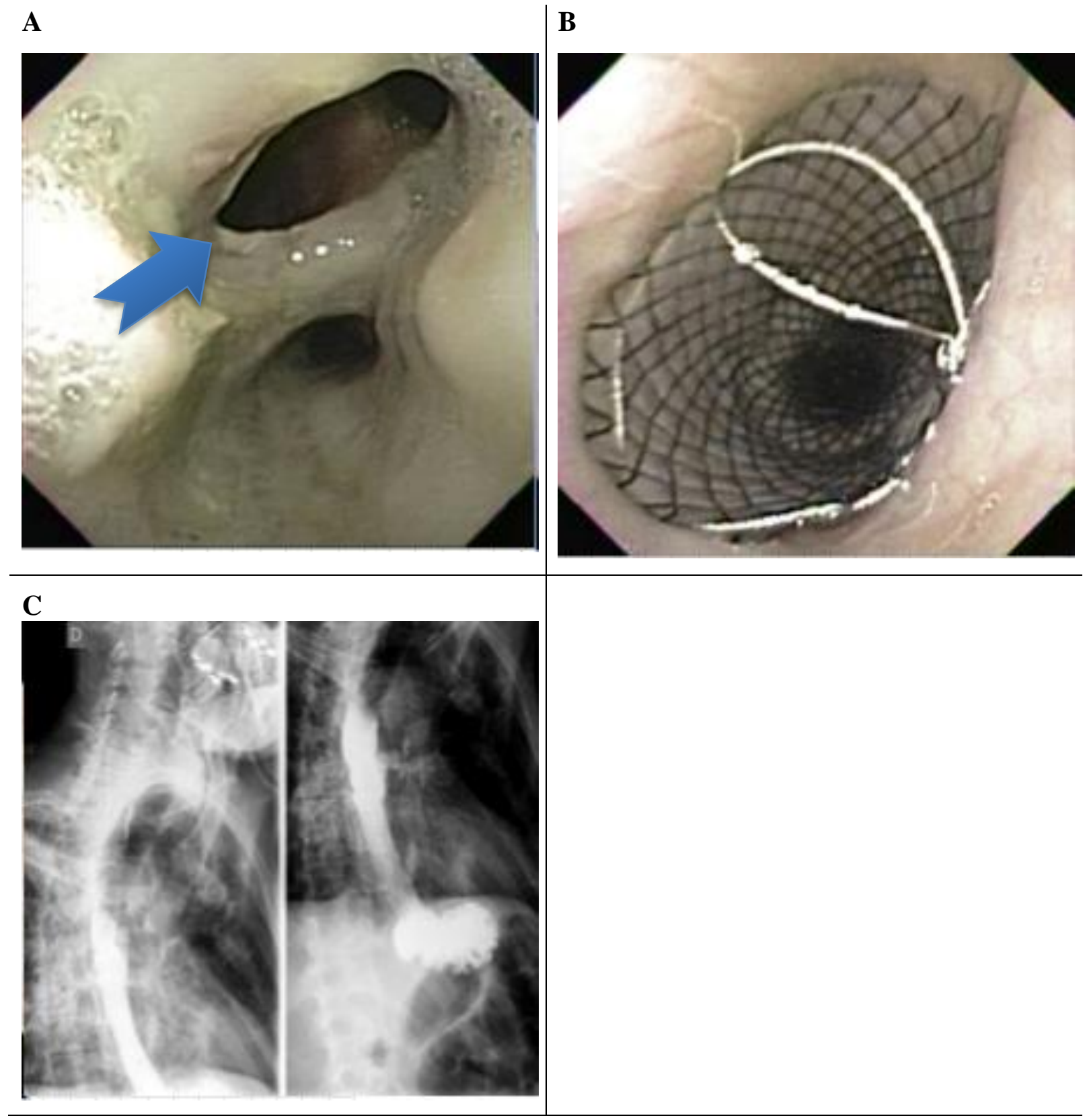

FigURA 4 - A: VISÃO ENDOSCÓPICA DA FÍSTULA ESOFÁGICA (SETA); B: VISÃO ENDOSCÓPICA DA PRÓTESE METÁLICA EXPANDIDA EM ESÔFAGO; C: INJEÇÃO DE MEIO DE CONTRASTE CONFIRMANDO A OCLUSÃO DA FÍSTULA PELA PRÓTESE (IMAGEM RADIOLÓGICA) 


\subsection{Seguimento}

No mesmo dia após o procedimento, foi introduzida dieta por via oral e observados sintomas de broncoaspiração.

Pacientes que permaneceram internados foram acompanhados por equipe multidisciplinar. Para os pacientes ambulatoriais foram dadas orientações nutricionais e prescrito esquema analgésico. Estes foram orientados a retornar 15 dias após o procedimento e, em seguida, mensalmente. Em caso de não comparecimento à consulta ambulatorial agendada, o paciente ou seu familiar foi contatado por telefone.

Todos os pacientes foram acompanhados até a data do óbito. Pacientes que permaneceram vivos, mas com seguimento por um período inferior a 15 dias, foram excluídos do estudo.

Considerou-se sucesso técnico conforme colocação da prótese em local previamente planejado, com completa oclusão da fístula confirmada por endoscopia e radiologia.

Considerou-se insucesso clínico:

- Persistência ou piora dos sintomas disfágicos associados à broncoaspiração durante a deglutição de alimentos e líquidos;

○ Persistência ou piora do quadro de infecção pulmonar após a passagem da PMAE;

- Recorrência da fístula esofagorrespiratória completamente ocluída nos primeiros 7 dias depois da passagem da PMAE.

A avaliação do grau de disfagia foi baseada em dados clínicos obtidos 15 dias após a passagem da prótese.

A avaliação do quadro pulmonar foi baseada em dados clínicos, como presença de febre, expectoração e dispneia, associado aos achados dos laudos dos exames de tomografia computadorizada ou radiografia de tórax. Episódios de infecção pulmonar com 
início após 15 dias do procedimento não foram associados à passagem da PMAE, desde que descartada a possibilidade de recorrência da FER por exames de imagem ou endoscopia.

Recorrência da fístula foi definida como reabertura de uma fístula previamente ocluída pela prótese, durante o seguimento. Fístulas que foram diagnosticadas em locais diferentes, após a passagem da PMAE, não foram consideradas recorrências, mas sim novas fístulas. 


\subsection{Eventos adversos}

Foi considerado evento adverso relacionado ao procedimento qualquer modificação desfavorável e não desejada da estrutura, função ou bioquímica do organismo, ou o agravamento de processos pré-existentes pelo tratamento endoscópico.

Os eventos adversos foram estratificados em precoces, se ocorridos em até 7 dias após o procedimento, e tardios, se ocorridos após 7 dias da passagem da prótese. ${ }^{44}$

Os possíveis eventos adversos que foram relacionados ao procedimento são:

- Insuficiência respiratória por compressão traqueal pela prótese: incapacidade do paciente em manter ventilação adequada (saturação de oxigênio maior que 90\%), necessitando de suporte, invasivo ou não.

- Perfuração esofágica: perfuração da parede esofágica durante dilatação, passagem do endoscópio ou mesmo ocasionada pela prótese.

- Hemorragia digestiva: hematêmese ou melena, associada à queda de hemoglobina maior que $2 \mathrm{~g} / \mathrm{dL}$ ou instabilidade hemodinâmica.

- Migração: deslocamento proximal ou distal da prótese em relação à localização inicial, com reabertura da fístula.

- Fístula esofágica: formação de nova fístula esofágica em uma das extremidades da prótese, causada por isquemia da parede esofágica.

- Obstrução da prótese por crescimento tumoral: obstrução da prótese por crescimento tumoral nas extremidades da mesma, com recorrência da disfagia.

- Impactação alimentar: obstrução da prótese por alimentos, resultando em disfagia.

$\mathrm{Na}$ figura 5, podemos observar a visão endoscópica de alguns tipos de eventos adversos relacionados às próteses metálicas. Nos casos de eventos adversos, o paciente foi tratado conforme protocolo institucional e os dados incluídos em planilha. 


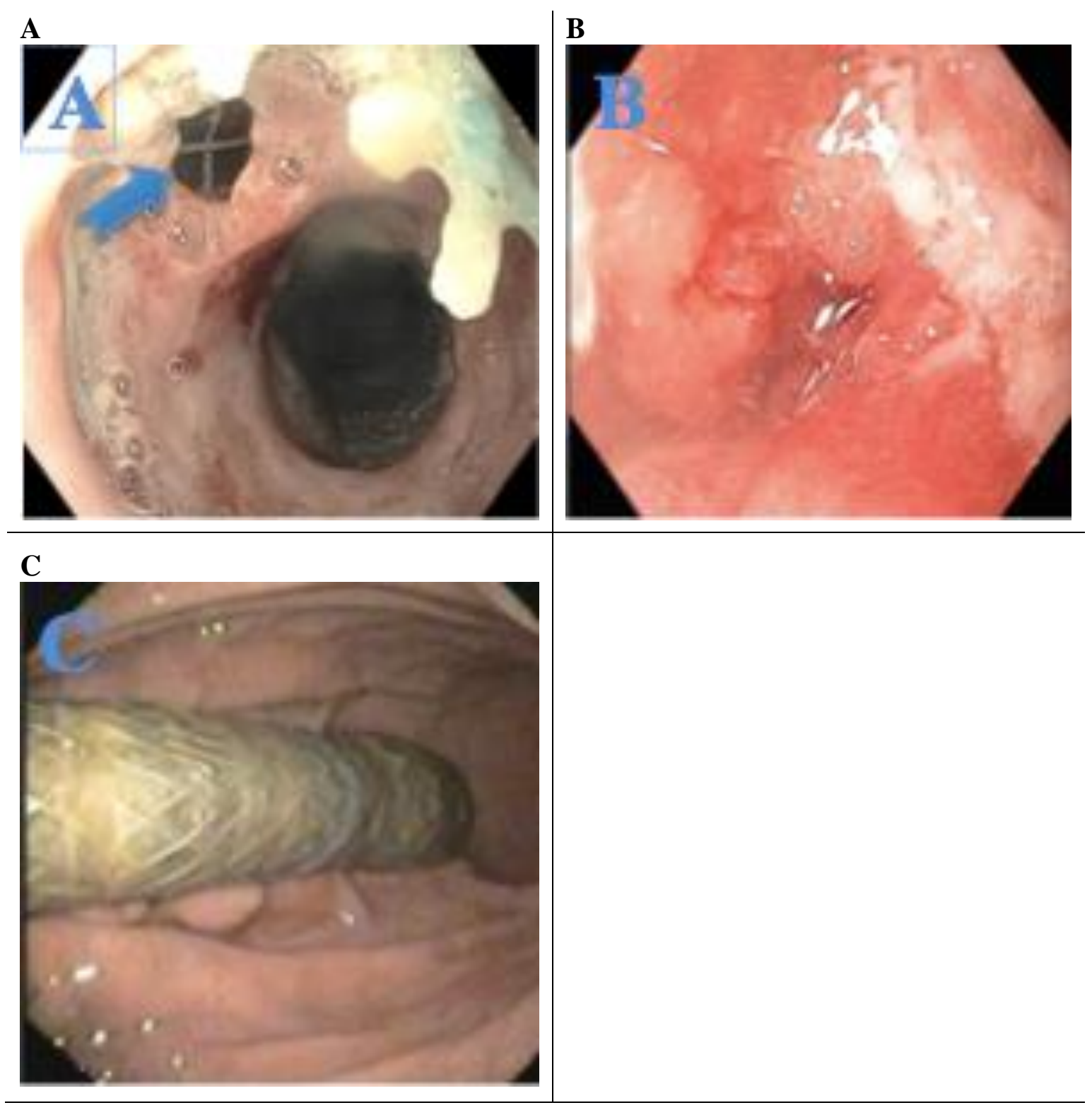

FiguRA 5 - VisÃO ENDOSCÓPICA DE EVENTOS ADVERSOS DAS PRÓTESES METÁLICAS: A: FÍSTULA ESOFÁGICA (SETA); B: OBSTRUÇÃO DA PRÓTESE POR CRESCIMENTO TUMORAL NA EXTREMIDADE PROXIMAL DA PRÓTESE; C: MIGRAÇÃO DISTAL DA PRÓTESE PARA O ESTÔMAGO 


\subsection{Análise estatística}

A análise estatística entre os grupos de sucesso e insucesso clínico após a passagem da PMAE foi feita utilizando parâmetros clínicos, radiológicos e endoscópicos. Os dados foram descritos por meio de média, mediana, quartis e desvio padrão para variáveis contínuas e de porcentagem para variáveis qualitativas. A análise descritiva foi ilustrada por meio de gráficos.

O teste Exato de Fisher foi utilizado para comparar as variáveis categorizadas como idade (superior ou igual a 60 anos e menor que 60 anos), sexo, diâmetro da fístula (maior ou menor do que $1 \mathrm{~cm}$ ), localização da fístula, ECOG, albumina sérica, momento do diagnóstico da fístula esofagorrespiratória, presença de doença pulmonar em atividade e tratamento oncológico prévio. Para variáveis contínuas, foi utilizado o teste $t$-student para comparar os grupos de sucesso e insucesso clínico quando a hipótese de normalidade foi satisfeita (verificada com o teste de Anderson-Darling) ou de Brunner-Munzel, quando não houve homogeneidade das variâncias (verificado pelo teste de Bartlett).

A significância estatística foi de $5 \%$ para todos os testes realizados. A regressão logística foi utilizada para estabelecer os fatores de impacto sobre o sucesso clínico, calculando-se a razão de chance (Odds Ratio - OR) com seus intervalos de confiança (IC $95 \%)$.

O modelo de regressão de Cox foi utilizado para avaliar o impacto de cada fator na sobrevida dos pacientes por meio de risco relativo (Relative Risk - RR) e também para estimar as curvas de sobrevida dos pacientes.

Toda análise foi realizada utilizando o programa $\mathrm{R}(R$ Project) versão 3.1.2. 


\subsection{Aspectos éticos}

O projeto foi enviado à Comissão de Ética para Análise de Projetos de Pesquisa do HC-FMUSP e foi aprovado pelo Conselho do Departamento de Gastroenterologia em 07 de maio de 2014, sob número 116/14. 


\section{RESULTADOS}

\subsection{Pacientes incluídos no estudo}

No período entre janeiro de 2009 e fevereiro de 2016, 335 pacientes com câncer esofágico avançado foram encaminhados ao Serviço de Endoscopia Digestiva do Instituto do Câncer do Estado de São Paulo (ICESP) para paliação dos sintomas através da passagem de prótese metálica autoexpansível. Destes, 76 pacientes possuíam fístula esofagorrespiratória. De acordo com os critérios de exclusão, três pacientes não foram elegíveis ao estudo, dos quais um possuía história de manipulação cirúrgica prévia e dois não tiveram a dosagem dos níveis séricos de albumina realizada.

Houve ainda perda de dois pacientes que inicialmente haviam sido incluídos no estudo. Ambos os pacientes tiveram perda precoce de seguimento, com apenas um e três dias de acompanhamento. Desta forma, 71 pacientes foram incluídos na análise estatística (Figura 6). 


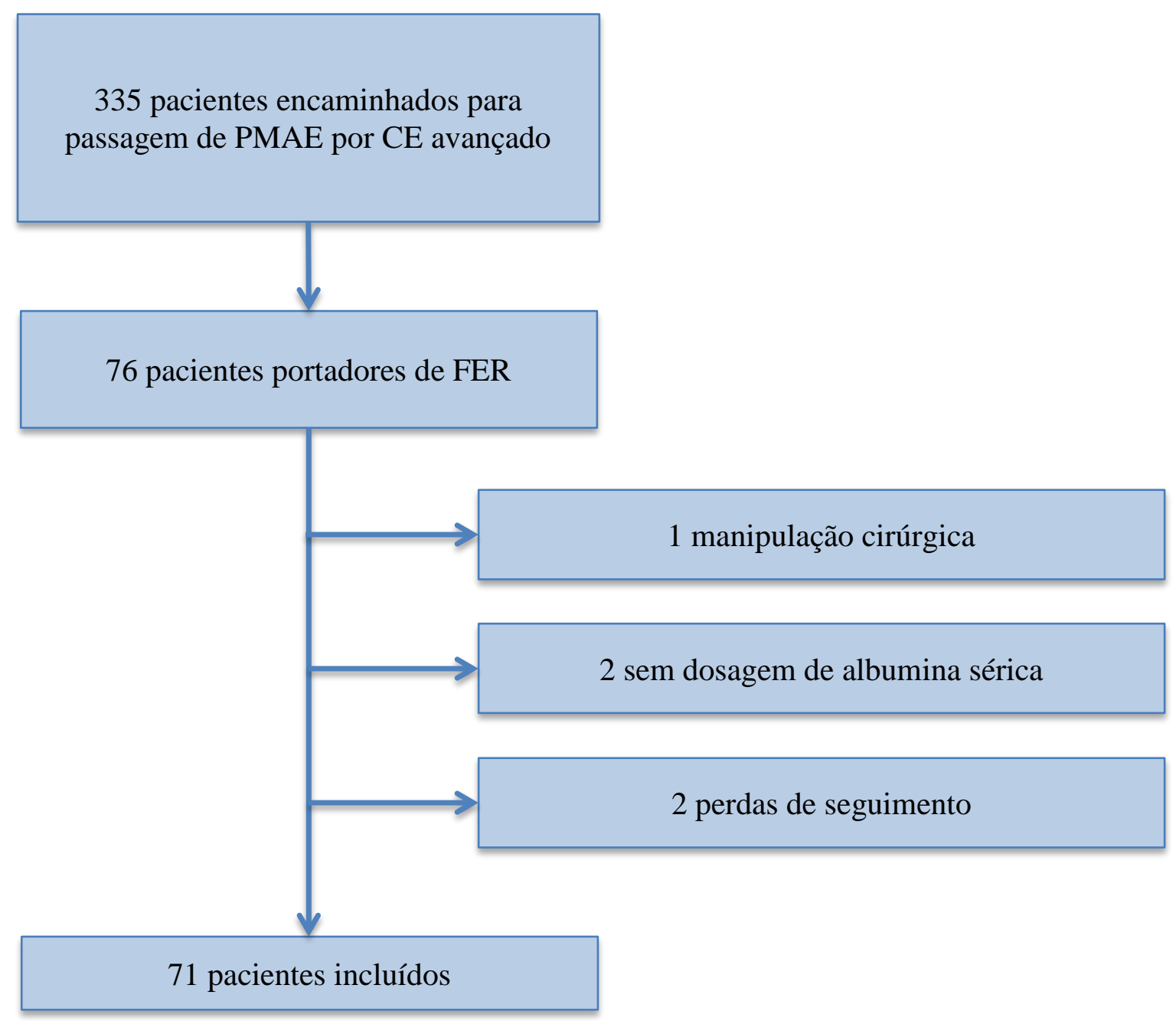

FIGURA 6 - FLUXOGRAMA DOS PACIENTES INCLUÍDOS NO ESTUDO 


\subsection{Dados demográficos e parâmetros clínicos}

Cinquenta e cinco $(77,5 \%)$ pacientes eram do sexo masculino e $16(22,5 \%)$ do feminino, com idade média de 59 anos $\pm 8,46$ anos, variando de 41 a 81 anos. A idade era menor do que 60 anos em 40 pacientes $(56,3 \%)$ e superior ou igual a 60 anos em 31 pacientes $(43,7 \%)$.

Em relação ao ECOG, cinco pacientes (7\%) foram classificados como ECOG 0, 21 deles $(29,6 \%)$ como ECOG 1, 25 pacientes $(35,2 \%)$ como ECOG 2, 19 pacientes $(26,8 \%)$ como ECOG 3 e apenas um único paciente $(1,4 \%)$ possuía ECOG 4.

Quatorze pacientes $(19,7 \%)$ apresentavam dosagem de albumina sérica dentro dos limites da normalidade no momento da passagem da PMAE. Vinte e oito $(39,4 \%)$ apresentavam depleção leve da albumina sérica, 17 (23,9\%) possuíam depleção moderada e 12 deles $(16,9 \%)$ apresentavam depleção intensa dos níveis séricos de albumina.

Quanto à história de tratamento oncológico prévio, 52 pacientes $(73,2 \%)$ não haviam sido submetidos a qualquer modalidade de tratamento ou haviam sido submetidos apenas a quimioterapia, enquanto 19 pacientes (26,8\%) haviam sido submetidos a radioterapia, isolada ou associada a quimioterapia.

Quarenta pacientes $(56,3 \%)$ já possuíam a fístula esofagorrespiratória no momento do diagnóstico do câncer esofágico avançado, enquanto que 31 deles (43,7\%) desenvolveram a fístula durante o tratamento do câncer esofágico.

Radiologicamente, 23 pacientes $(32,4 \%)$ não apresentavam doença pulmonar no momento da passagem da prótese, enquanto 48 pacientes $(67,6 \%)$ tinham diagnóstico de broncopneumonia e/ou abscesso pulmonar.

Em média, o grau de disfagia era de 3,82 $\pm 0,62$, variando de 1 a 4 .

Os dados demográficos e parâmetros clínicos dos pacientes estão na Tabela 1. 
TABELA 1: DADOS DEMOGRÁFICOS E PARÂMETROS CLÍNICOS DOS PACIENTES ESTUDADOS

Variável

Total de pacientes $n=71(\%)$

\begin{tabular}{cc}
\hline Idade (anos)* & $59 \pm 8,46$ \\
$\quad<60$ anos & $40(56,3)$ \\
$\geq 60$ anos & $31(43,7)$ \\
Sexo & \\
\hline Feminino & $16(22,5)$ \\
$\quad$ Masculino & $55(77,5)$ \\
ECOG & \\
\hline 0,1 e 2 & $51(71,8)$ \\
3 e 4 & $20(28,2)$
\end{tabular}

\section{Albumina Sérica}

Normal e Depleção Leve

$42(59,2)$

Depleção Moderada e Intensa

$29(40,8)$

\section{Desenvolvimento da Fístula}

Ao diagnóstico do tumor

$40(56,3)$

Durante o tratamento do tumor

$31(43,7)$

\section{Tratamento Oncológico}

Nenhum/Quimioterapia

$52(73,2)$

Radioterapia/Radio + Quimioterapia

$19(26,8)$

\section{Doença Pulmonar}

Ausente

$23(32,4)$

BCP/Abscesso

$48(67,6)$

\section{Disfagia}

$3,82(1-4)$

*Valores representados média e desvio-padrão; demais em frequências seguidos de valores percentuais. 


\subsection{Parâmetros endoscópicos e radiológicos}

Em relação ao diagnóstico anatomopatológico, todas as neoplasias eram carcinoma de células escamosas. $O$ tamanho médio da lesão era de $8,31 \mathrm{~cm} \pm 2,68 \mathrm{~cm}$, variando de 3 $\mathrm{cm}$ a $17 \mathrm{~cm}$.

Em 54 casos (76,1\%), a fístula encontrada era do tipo traqueobrônquica e em 17 casos $(23,9 \%)$, do tipo pleuropulmonar. Quanto ao diâmetro da fístula, o tamanho era igual ou superior a $1 \mathrm{~cm}$ em 34 pacientes (47,9\%) e menor que $1 \mathrm{~cm}$ em 37 pacientes $(52,1 \%)$.

Os dados endoscópicos e radiológicos das neoplasias estão na Tabela 2. 
TABELA 2: PARÂMETROS ENDOSCÓPICOS E RADIOLÓGICOS DOS PACIENTES ESTUDADOS

Variável

Total de pacientes $n=71(\%)$

\section{Tipo Histológico}

Carcinoma de Células Escamosas

$71(100)$

Tamanho médio da lesão $(\mathrm{cm})^{*}$

$8,31 \pm 2,68$

\section{Localização da Fístula}

Pleuropulmonar

$17(23,9)$

Traqueobrônquica

$54(76,1)$

Diâmetro da Fístula
$\geq 1 \mathrm{~cm}$
$34(47,9)$
$<1 \mathrm{~cm}$
$37(52,1)$

*Valores representado em média e desvio-padrão, demais em frequências seguidos de valores percentuais 


\subsection{Procedimento endoscópico}

O sucesso técnico observado foi de $98,6 \%$. Houve 1 caso de insucesso técnico em decorrência de lesão esofágica intransponível ao fio guia, o que impossibilitou a passagem da prótese. Este paciente foi encaminhado para realização de gastrostomia cirúrgica. Desta forma, 70 pacientes foram submetidos à passagem de prótese metálica com sucesso.

Ao total foram utilizadas 77 próteses metálicas autoexpansíveis, sendo 74 delas parcialmente recobertas e 3 totalmente recobertas. O comprimento das próteses variou de $8 \mathrm{~cm}$ a $15 \mathrm{~cm}$ e o diâmetro, de $18 \mathrm{~mm}$ a $23 \mathrm{~mm}$. As marcas das próteses utilizadas foram: Evolution (Cook Endoscopy, Winston-Salem, NC) ( $\mathrm{n}=45)$, Wallflex (Boston Scientific, Natick, MA) (n=16), Hanarostent (M.I. Tech, Seoul, Korea) $(n=8)$, Choostent (Solco Intermed Co., Seoul, Korea) (n=6) e Ultraflex (Boston Scientific, Natick, MA, US) (n=2).

Cinco pacientes colocaram mais de uma prótese para o manejo das complicações que ocorreram.

Em quatro pacientes foram necessárias dilatações endoscópicas para a passagem da PMAE. 


\subsection{Resultados quanto ao desfecho clínico}

Trinta e nove pacientes $(55,7 \%)$ tiveram sucesso clínico com o tratamento e 31 pacientes $(44,3 \%)$ tiveram insucesso clínico com a PMAE. A média de idade dos pacientes que obtiveram sucesso clínico foi de 59 anos \pm 7,8 anos, variando de 43 anos a 74 anos. Já a média de idade dos pacientes com insucesso clínico foi de 59 anos, $\pm 9,56$ anos, variando de 41 anos a 81 anos.

Os dados demográficos e parâmetros clínicos dos pacientes quanto ao desfecho clínico estão na Tabela 3. 
TABELA 3: DADOS DEMOGRÁFICOS E PARÂMETROS CLÍNICOS DOS PACIENTES QUANTO AO DESFECHO CLÍNICO

\begin{tabular}{|c|c|c|}
\hline \multirow{2}{*}{ Variável } & Sucesso Clínico & Insucesso Clínico \\
\hline & $\mathrm{n}=39(\%)$ & $\mathrm{n}=31(\%)$ \\
\hline \multicolumn{3}{|l|}{ Idade } \\
\hline$<60$ anos & $22(56,4)$ & $17(54,8)$ \\
\hline$\geq 60$ anos & $17(43,6)$ & $14(45,2)$ \\
\hline \multicolumn{3}{|l|}{ Sexo } \\
\hline Feminino & $7(17,9)$ & $9(29)$ \\
\hline Masculino & $32(82,1)$ & $22(71)$ \\
\hline \multicolumn{3}{|l|}{ ECOG } \\
\hline 0,1 e 2 & $35(89,7)$ & $16(51,6)$ \\
\hline 3 e 4 & $4(10,3)$ & $15(48,4)$ \\
\hline \multicolumn{3}{|l|}{ Albumina Sérica } \\
\hline Normal e Depleção Leve & $27(69,2)$ & $14(45,2)$ \\
\hline Depleção Moderada e Intensa & $12(30,8)$ & $17(54,8)$ \\
\hline \multicolumn{3}{|l|}{ Desenvolvimento da Fístula } \\
\hline Ao diagnóstico do tumor & $26(66,7)$ & $13(41,9)$ \\
\hline Durante o tratamento do tumor & $13(33,3)$ & $18(58,1)$ \\
\hline \multicolumn{3}{|l|}{ Tratamento Oncológico } \\
\hline Nenhum/Quimioterapia & $32(82,1)$ & $19(61,3)$ \\
\hline Radioterapia/Radio + Quimioterapia & $7(17,9)$ & $12(38,7)$ \\
\hline \multicolumn{3}{|l|}{ Doença Pulmonar } \\
\hline Ausente & $16(41)$ & $7(22,6)$ \\
\hline $\mathrm{BCP} / \mathrm{Abscesso}$ & $23(59)$ & $24(77,4)$ \\
\hline
\end{tabular}


Os parâmetros endoscópicos e radiológicos dos pacientes quanto ao desfecho clínico estão na Tabela 4.

TABELA 4: PARÂMETROS ENDOSCÓPICOS E RADIOLÓGICOS DOS PACIENTES QUANTO AO DESFECHO CLÍNICO

\begin{tabular}{ccc} 
Variável & $\begin{array}{c}\text { Sucesso Clínico } \\
\mathbf{n = 3 9}(\boldsymbol{\%})\end{array}$ & $\begin{array}{c}\text { Insucesso Clínico } \\
\mathbf{n}=\mathbf{3 1}(\boldsymbol{\%})\end{array}$ \\
\hline Localização da Fístula & $7(17,9)$ & $10(32,3)$ \\
\hline Pleuropulmonar & $32(82,1)$ & $21(67,7)$ \\
Traqueobrônquica & & $11(35,5)$ \\
Diâmetro da Fístula & $25(64,1)$ & $20(64,5)$ \\
\hline$<1 \mathrm{~cm}$ & $14(35,9)$ & \\
\hline
\end{tabular}




\subsubsection{Análise dos dados demográficos e parâmetros clínicos quanto ao desfecho clínico}

Não houve diferença estatística quanto ao desfecho clínico em relação à idade, sexo, nível de albumina sérico, momento do diagnóstico da fístula, tratamentos oncológicos previamente realizados ou doença pulmonar em atividade no momento da passagem da PMAE. No entanto, os resultados mostraram que houve associação entre ECOG e o desfecho clínico. Pacientes com ECOG 3 e 4 tiveram mais insucesso clínico quando comparados à pacientes com ECOG 0, 1 e 2 (Gráfico 1).

\section{ECOG}

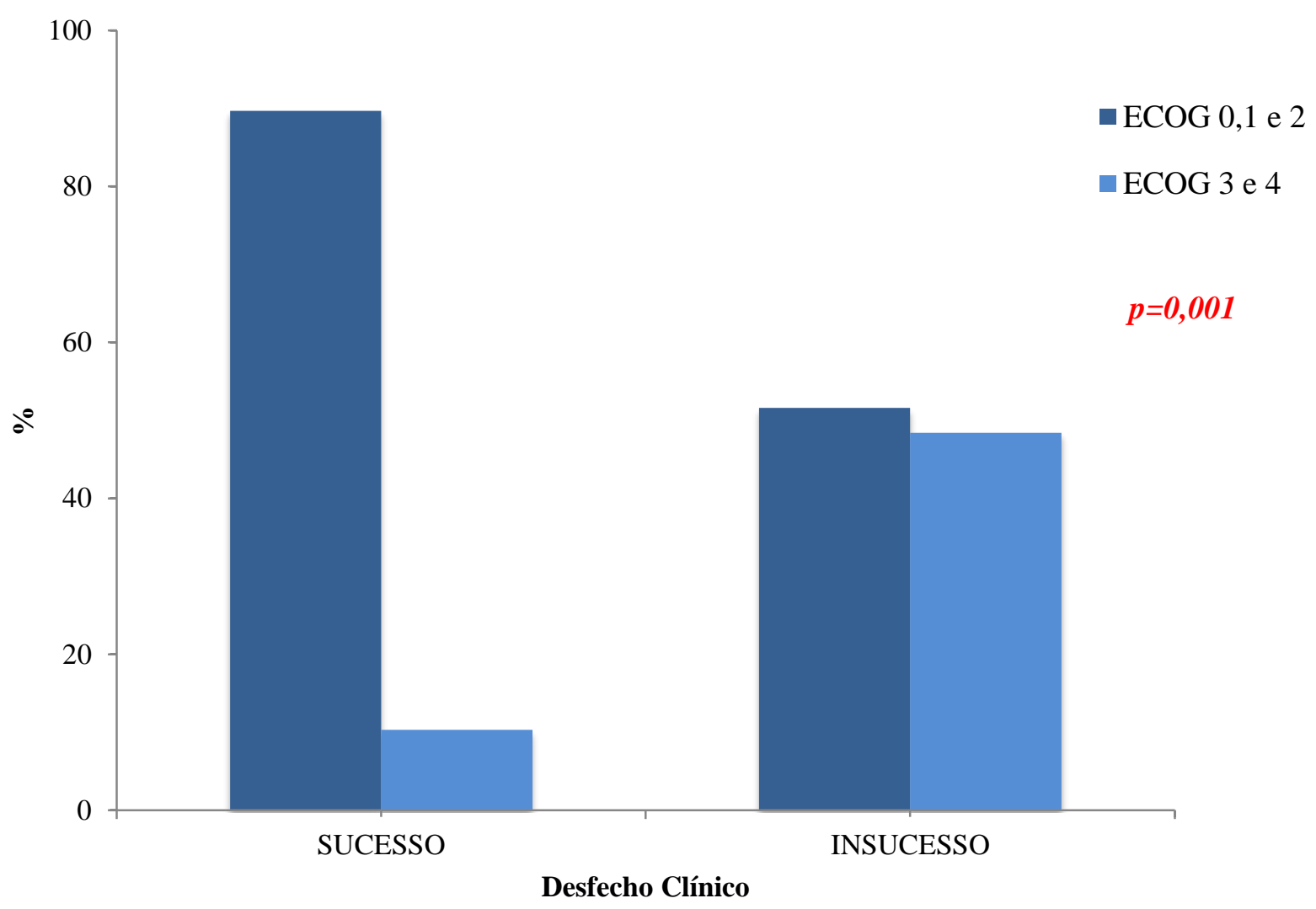

GráFICO 1: ASSOCIAÇÃO ENTRE ECOG E O DESFECHO CLÍNICO 
As associações entre desfecho clínico versus dados demográficos e parâmetros clínicos estão descritas na Tabela 5.

TABELA 5: COMPARAÇÃO ENTRE OS DADOS DEMOGRÁFICOS E PARÂMETROS CLÍNICOS DOS PACIENTES QUANTO AO DESFECHO CLÍNICO

\begin{tabular}{|c|c|c|c|}
\hline Variável & $\begin{array}{c}\text { Sucesso Clínico } \\
\text { n=39 }(\%)\end{array}$ & $\begin{array}{c}\text { Insucesso Clínico } \\
\mathbf{n = 3 1}(\%)\end{array}$ & $p$ \\
\hline \multicolumn{4}{|l|}{ Idade } \\
\hline$<60$ anos & $22(56,4)$ & $17(54,8)$ & \multirow{2}{*}{1} \\
\hline$\geq 60$ anos & $17(43,6)$ & $14(45,2)$ & \\
\hline \multicolumn{4}{|l|}{ Sexo } \\
\hline Feminino & $7(17,9)$ & $9(29)$ & \multirow{2}{*}{0,391} \\
\hline Masculino & $32(82,1)$ & $22(71)$ & \\
\hline \multicolumn{4}{|l|}{ ECOG } \\
\hline 0,1 e 2 & $35(89,7)$ & $16(51,6)$ & \multirow{2}{*}{0,001} \\
\hline 3 e 4 & $4(10,3)$ & $15(48,4)$ & \\
\hline \multicolumn{4}{|l|}{ Albumina Sérica } \\
\hline Normal e Depleção Leve & $27(69,2)$ & $14(45,2)$ & \multirow{2}{*}{0,053} \\
\hline Depleção Moderada e Intensa & $12(30,8)$ & $17(54,8)$ & \\
\hline \multicolumn{4}{|l|}{ Desenvolvimento da Fístula } \\
\hline Ao diagnóstico do tumor & $26(66,7)$ & $13(41,9)$ & \multirow{2}{*}{0,053} \\
\hline Durante o tratamento do tumor & $13(33,3)$ & $18(58,1)$ & \\
\hline \multicolumn{4}{|l|}{ Tratamento Oncológico } \\
\hline Nenhum/Quimioterapia & $32(82,1)$ & $19(61,3)$ & \multirow{2}{*}{0,063} \\
\hline $\begin{array}{l}\text { Radioterapia/Radio + } \\
\text { Quimioterapia }\end{array}$ & $7(17,9)$ & $12(38,7)$ & \\
\hline \multicolumn{4}{|l|}{ Doença Pulmonar } \\
\hline Ausente & $16(41)$ & $7(22,6)$ & \multirow{2}{*}{0,128} \\
\hline $\mathrm{BCP} / \mathrm{Abscesso}$ & $23(59)$ & $24(77,4)$ & \\
\hline
\end{tabular}


A regressão logística simples demonstrou que entre as variáveis demográficas e clínicas, tanto o ECOG quanto o nível sérico da albumina e o momento do desenvolvimento da fístula foram fatores preditivos para o insucesso clínico. Pacientes com ECOG 3 e 4 tiveram cerca de 8,2 vezes mais chance de ter insucesso clínico em relação aos pacientes com ECOG 0,1 e 2 (IC 95\% 2,35 - 28,72, p=0,001). Pacientes com depleção moderada ou intensa da albumina sérica no momento da passagem da prótese tiveram 2,7 mais chance de ter insucesso clínico em relação aos pacientes com albumina sérica normal ou com depleção leve (IC 95\% 1,02 - 7,29, p=0,045). O mesmo aconteceu com pacientes que desenvolveram a fístula durante o tratamento do câncer esofágico, estes tiveram 2,7 mais chance de insucesso quando comparados aos pacientes que possuíam a fístula já ao diagnóstico do câncer de esôfago (IC 95\% 1,04 - 7,35, p=0,041) (Tabela 6). No entanto, após regressão logística múltipla, apenas ECOG 3 e 4 (OR 11,1, IC 95\% 2,17 $56,91, p=0,003)$ e o desenvolvimento da fístula durante o tratamento do câncer esofágico (OR 5,50, IC 95\% 1,29 - 23,36, $p=0,02)$ foram fatores preditivos para insucesso clínico. 
TABELA 6: DADOS DEMOGRÁFICOS E PARÂMETROS CLÍNICOS DOS PACIENTES QUANTO AOS FATORES PREDITIVOS DO INSUCESSO CLÍNICO

\begin{tabular}{|c|c|c|c|}
\hline Variável & OR & IC $95 \%$ & $p$ \\
\hline \multicolumn{4}{|l|}{ Idade } \\
\hline$<60$ anos & 1 & - & - \\
\hline$\geq 60$ anos & 1,07 & $0,41-2,75$ & 0,895 \\
\hline \multicolumn{4}{|l|}{ Sexo } \\
\hline Feminino & 1 & - & - \\
\hline Masculino & 0,53 & $0,17-1,65$ & 0,276 \\
\hline \multicolumn{4}{|l|}{ ECOG } \\
\hline 0,1 e 2 & 1 & - & - \\
\hline 3 e 4 & 8,21 & $2,35-28,72$ & 0,001 \\
\hline \multicolumn{4}{|l|}{ Albumina Sérica } \\
\hline Normal e Depleção Leve & 1 & - & - \\
\hline Depleção Moderada e Intensa & 2,73 & $1,02-7,29$ & 0,045 \\
\hline \multicolumn{4}{|l|}{ Desenvolvimento da Fístula } \\
\hline Ao diagnóstico do tumor & 1 & - & - \\
\hline Durante o tratamento do tumor & 2,77 & $1,04-7,35$ & 0,041 \\
\hline \multicolumn{4}{|l|}{ Tratamento Oncológico } \\
\hline Nenhum/Quimioterapia & 1 & - & - \\
\hline $\begin{array}{l}\text { Radioterapia/Radio + } \\
\text { Quimioterapia }\end{array}$ & 2,89 & $0,97-8,6$ & 0,057 \\
\hline \multicolumn{4}{|l|}{ Doença Pulmonar } \\
\hline Ausente & 1 & - & - \\
\hline $\mathrm{BCP} / \mathrm{Abscesso}$ & 2,38 & $0,83-6,86$ & 0,107 \\
\hline
\end{tabular}




\subsubsection{Análise dos parâmetros endoscópicos e radiológicos quanto ao desfecho clínico}

Não houve significância estatística quanto ao desfecho clínico entre pacientes com fístulas traqueobrônquicas e pleuropulmonares. Entretanto, fístulas com diâmetro $\geq 1 \mathrm{~cm}$, foram associadas ao insucesso clínico (Gráfico 2).

\section{Diâmetro da Fístula}

100

$<1 \mathrm{~cm}$

80 $\square \geq 1 \mathrm{~cm}$

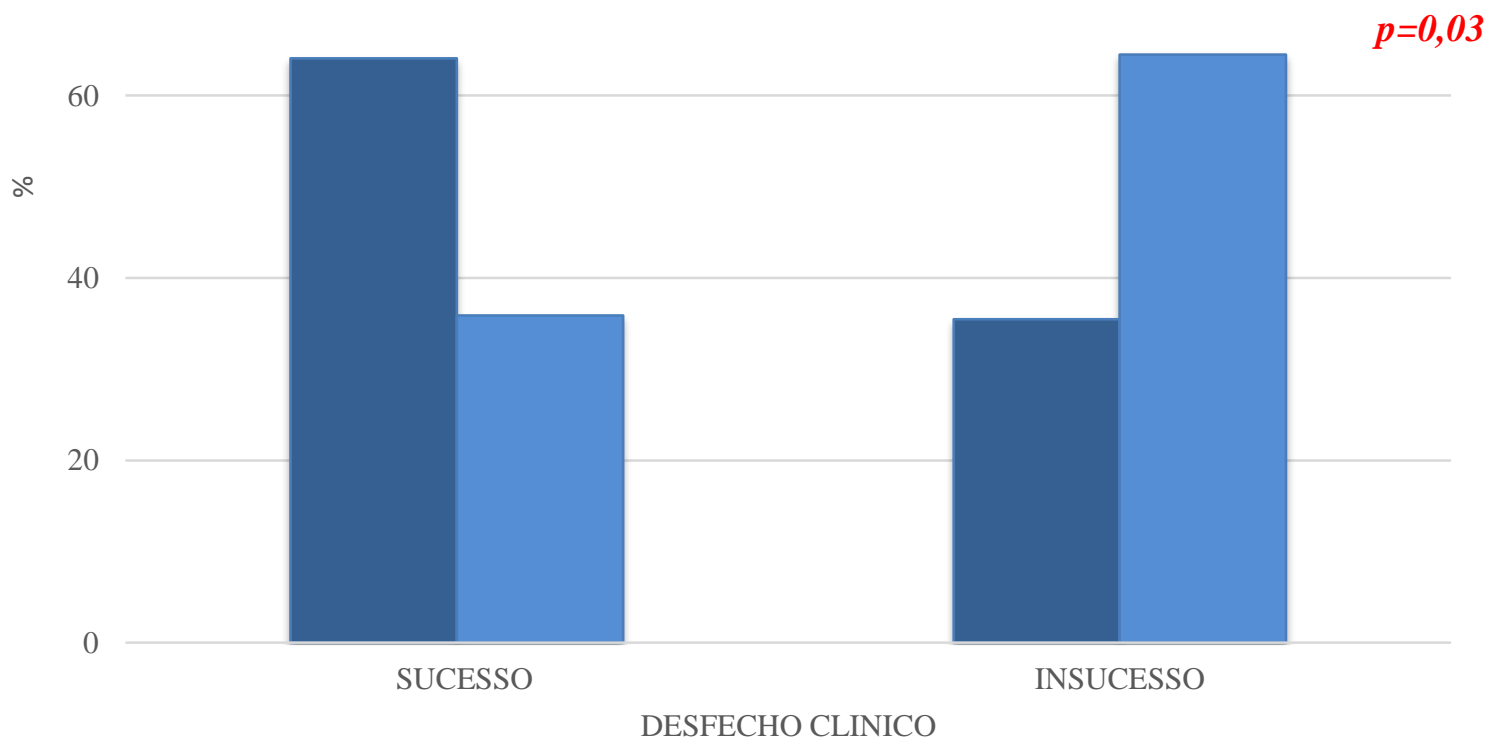

GRÁFICO 2: ASSOCIAÇÃO ENTRE DIÂMETRO DA FÍSTULA E O DESFECHO CLÍNICO 
$\mathrm{Na}$ Tabela 7, observa-se as associações entre os parâmetros endoscópicos e radiológicos quanto ao desfecho clínico.

TABELA 7: COMPARAÇÃO ENTRE OS PARÂMETROS ENDOSCÓPICOS E RADIOLÓGICOS DOS PACIENTES QUANTO AO DESFECHO CLÍNICO

\begin{tabular}{cccc} 
Variável & Sucesso Clínico & Insucesso Clínico & $\boldsymbol{p}$ \\
\hline Localização da Fístula & $\mathrm{n}=39(\%)$ & $\mathrm{n}=31(\%)$ & \\
\hline Pleuropulmonar & $7(17,9)$ & $10(32,3)$ & 0,262 \\
Traqueobrônquica & $32(82,1)$ & $21(67,7)$ & \\
Diâmetro da Fístula & & & \\
$<1 \mathrm{~cm}$ & $25(64,1)$ & $11(35,5)$ & $\mathbf{0 , 0 3}$ \\
$\geq 1 \mathrm{~cm}$ & $14(35,9)$ & $20(64,5)$ & \\
\hline
\end{tabular}

Entre os parâmetros endoscópicos e radiológicos, apenas a variável diâmetro da fístula igual ou superior a $1 \mathrm{~cm}$ foi fator preditivo para o insucesso clínico após regressão logística simples (IC 95\% 1,21 - 8,69, p=0,019) (Tabela 8). Assim, pacientes com fístulas maiores ou iguais a $1 \mathrm{~cm}$ possuem três vezes mais chance de ter insucesso clínico se comparados àqueles com fístulas de menor diâmetro. A análise multivariada confirmou que o diâmetro da fístula igual ou superior a $1 \mathrm{~cm}$ foi fator preditivo para o insucesso clínico (OR 4,88, IC 95\% 1,20 - 19,76, p=0,02).

TABELA 8: PARÂMETROS ENDOSCÓPICOS E RADIOLÓGICOS DOS PACIENTES QUANTO AOS FATORES PREDITIVOS DO INSUCESSO CLÍNICO

\begin{tabular}{cccc}
\hline \multicolumn{1}{c}{ Variável } & OR & IC 95\% & $\boldsymbol{p}$ \\
\hline Localização da Fístula & & & \\
\hline $\begin{array}{c}\text { Pleuropulmonar } \\
\text { Traqueobrônquica }\end{array}$ & 0,46 & $0,15-1,4$ & 0,17 \\
\hline Diâmetro da Fístula & & & \\
$<1 \mathrm{~cm}$ & 1 & - & - \\
$\geq 1 \mathrm{~cm}$ & 3,25 & $1,21-8,69$ & $\mathbf{0 , 0 1 9}$ \\
\hline
\end{tabular}




\subsection{Resultados quanto ao grau de disfagia}

O grau médio de disfagia previamente à passagem da PMAE era de 3,82 $\pm 0,62$, variando de 1 a 4 . Sessenta e quatro pacientes $(90,1 \%$ ) eram afágicos (grau 4) e dependiam de suporte nutricional por sonda nasoenteral, gastrostomia ou jejunostomia. Três pacientes $(4,2 \%)$ apresentavam disfagia para líquidos (grau 3), dois pacientes $(2,8 \%)$ apresentavam disfagia para alimentos pastosos (grau 2) e dois pacientes $(2,8 \%)$ referiam disfagia para alimentos sólidos (grau 1) (Gráfico 3).

\section{Disfagia Antes}

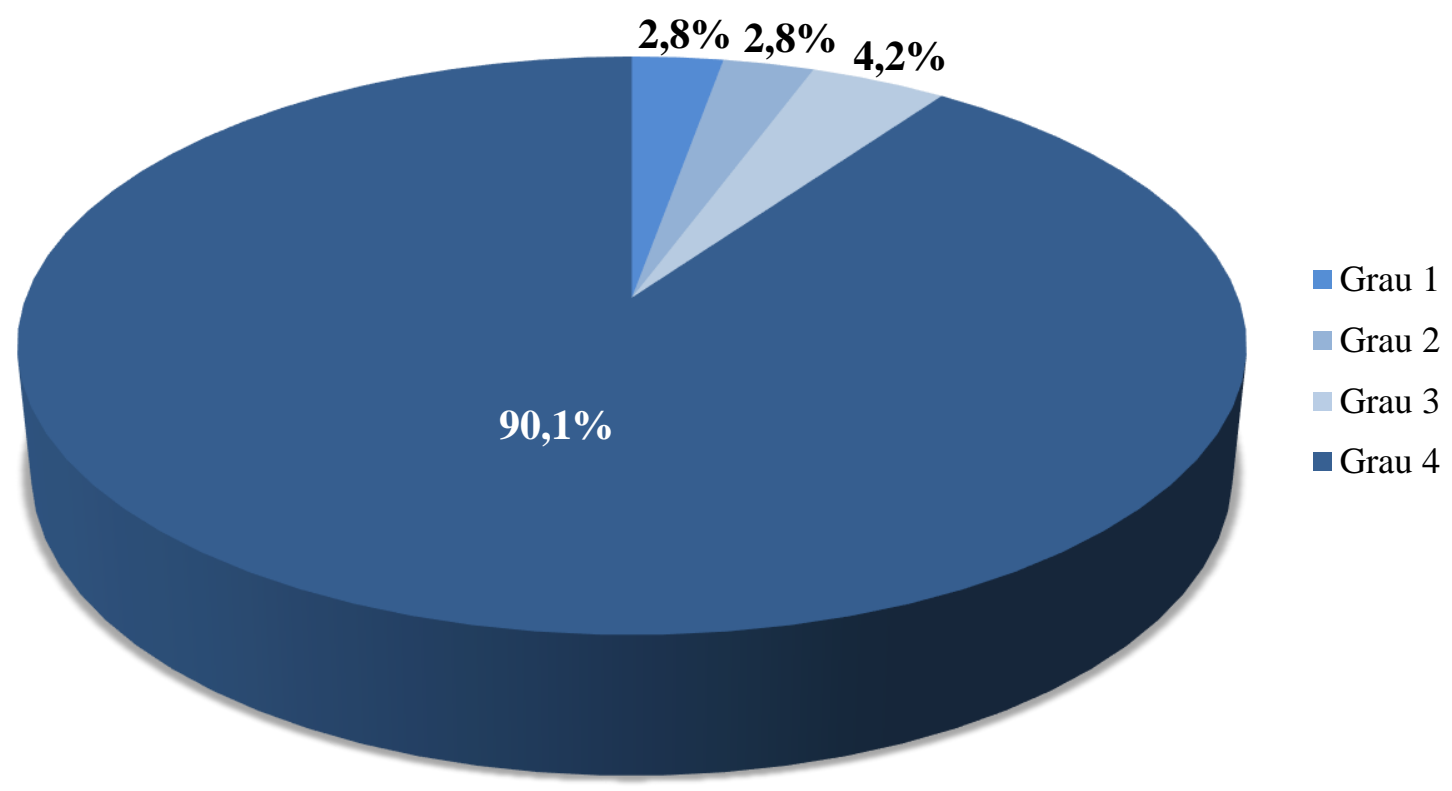

GRÁFICO 3: DISTRIBUIÇÃO DOS PACIENTES EM RELAÇÃO AO GRAU DE DISFAGIA ANTES DA PMAE

Após quinze dias da passagem da PMAE, o grau médio de disfagia foi de 2,31 \pm 1,37, variando de 1 a 4 . Vinte e cinco pacientes (35,7\%) estavam afágicos, cinco pacientes $(7,1 \%)$ apresentavam disfagia para líquidos, oito pacientes $(11,4 \%)$ apresentavam disfagia para alimentos pastosos e trinta e dois $(45,7 \%)$ referiam disfagia apenas para alimentos sólidos (Gráfico 4). 


\section{Disfagia Após}

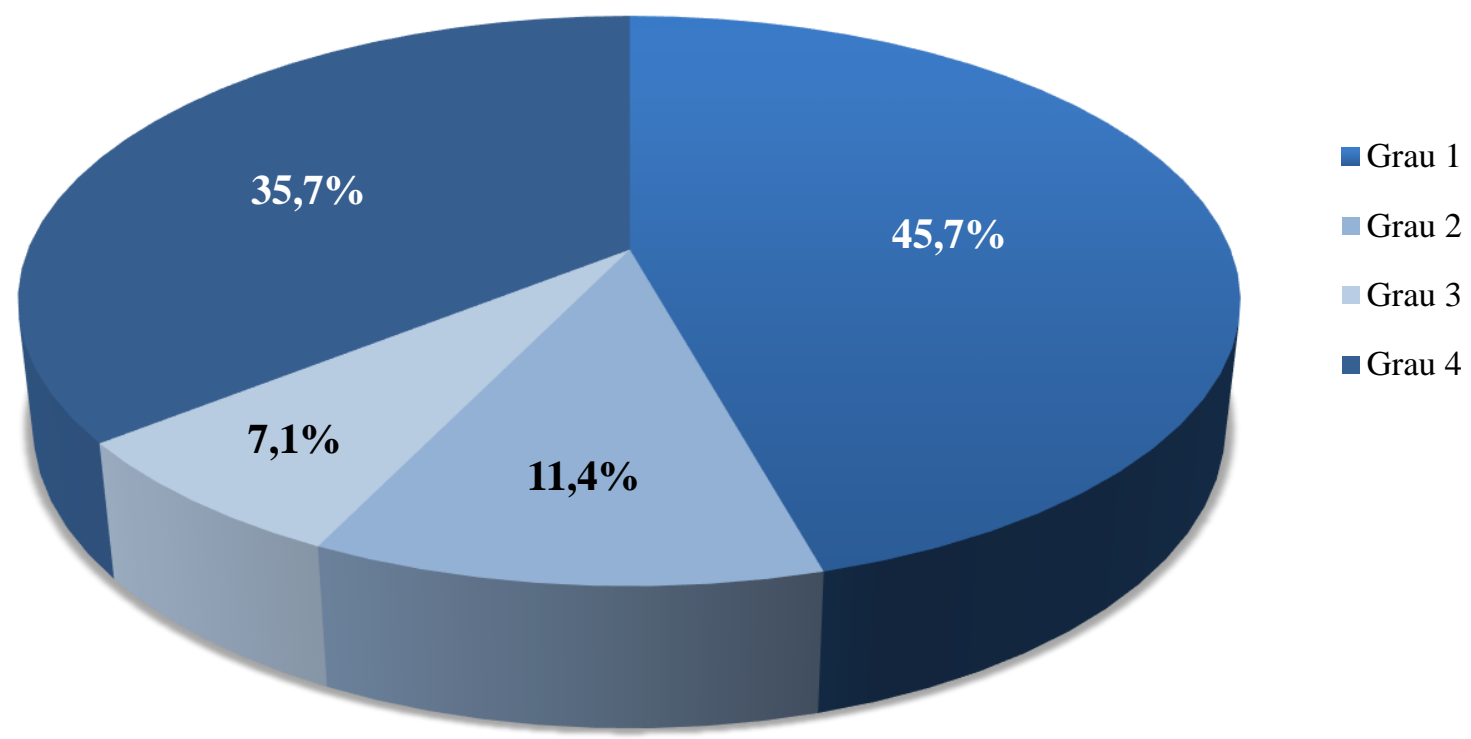

GRÁFICO 4: DISTRIBUIÇÃO DOS PACIENTES EM RELAÇÃO AO GRAU DE DISFAGIA 15 DIAS APÓS A PMAE

Foi utilizado o teste não paramétrico de Mann-Whitney pareado para a comparação da disfagia antes e após o procedimento. Quinze dias após a passagem da PMAE observouse melhora significativa no grau da disfagia referido pelos pacientes $(p<0,0001)$ (Gráfico $5)$. 


\section{Grau de Disfagia}

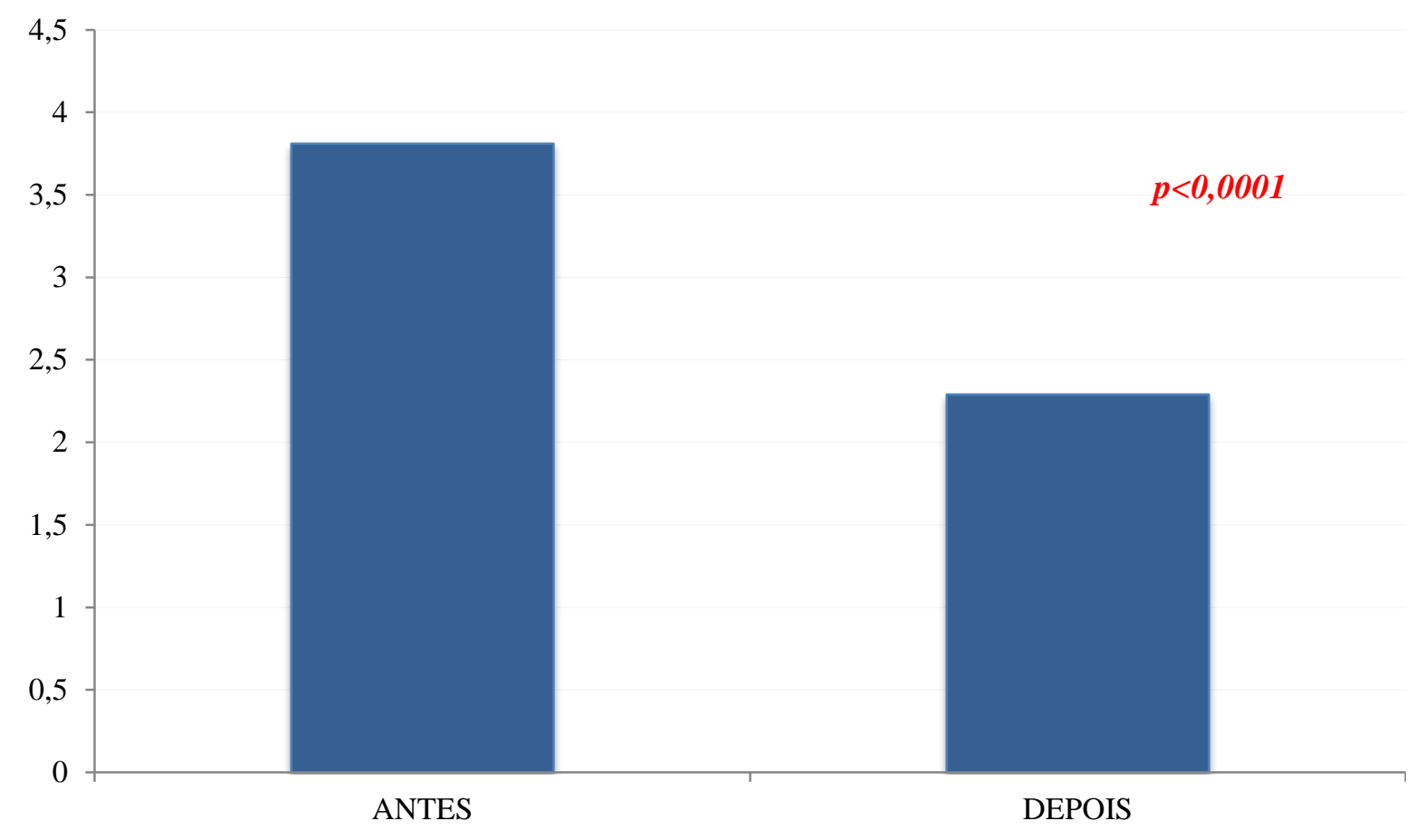

GRÁFICO 5: COMPARAÇÃO ENTRE OS GRAUS DE DISFAGIA ANTES E APÓS A PMAE 


\subsection{Resultados quanto à sobrevida}

A sobrevida global média obtida foi de 111,3 dias $\pm 115,8$ dias, variando de 1 - 487 dias. Considerando a sobrevida média apenas dos pacientes que obtiveram sucesso clínico, esta foi de 179 dias $\pm 113,8$ dias, variando de 31 - 487 dias. Já a sobrevida média dos pacientes que tiveram insucesso clínico foi de 25,4 dias $\pm 27,97$ dias, variando de 1 - 143 dias. Foi observada diferença estatística entre sucesso e insucesso clínico quanto à sobrevida $(p<0,0001)$ (Gráfico 6).

\section{Sobrevida Média}

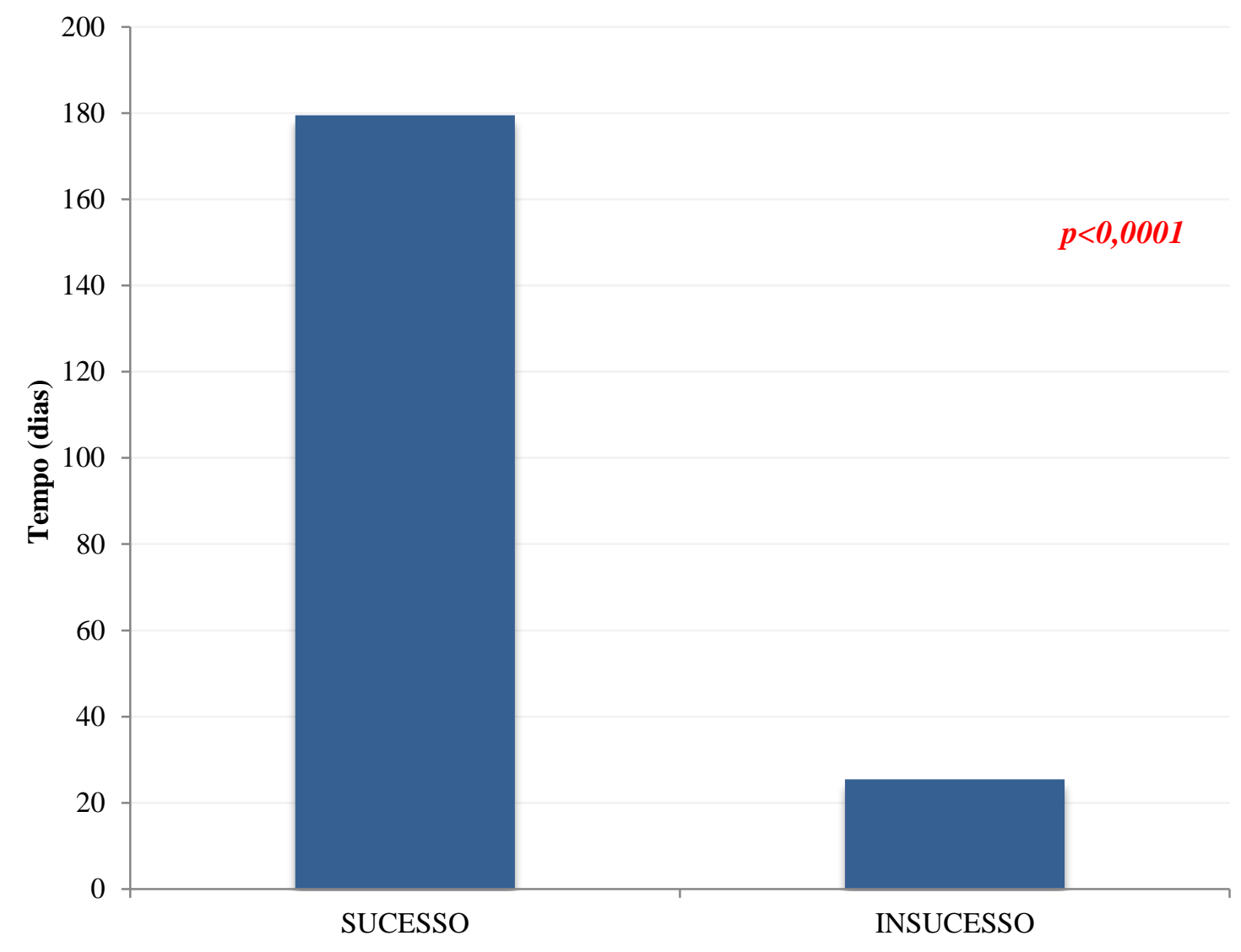

GRÁFICO 6: SOBREVIDA DOS PACIENTES QUANTO OS GRUPOS DE SUCESSO E INSUCESSO CLÍNICO 


\subsubsection{Análise dos dados demográficos e parâmetros clínicos quanto à sobrevida}

Após regressão simples através da regressão de Cox observou-se que idade, sexo, nível sérico da albumina ou o momento do desenvolvimento da fístula não impactaram a sobrevida dos pacientes. No entanto, ECOG 3 e 4 (Gráfico 7), presença de doença pulmonar infecciosa em atividade no momento da passagem da PMAE (Gráfico 8) e tratamentos oncológicos prévios com radioterapia, isolada ou associada à quimioterapia (Gráfico 9), impactaram negativamente a sobrevida. A regressão múltipla confirmou ECOG 3 e 4 (RR 3,15; IC 95\% 1,67 - 5,94; p<0,001), infecção pulmonar em atividade no momento da passagem da PMAE (RR 2,19, IC 95\% 1,19 - 4,02 p=0,01) e tratamento oncológico prévio com radioterapia (RR 2,06, IC 95\% 1,12 - 3,79, p=0,01) como fatores preditivos de menor sobrevida.

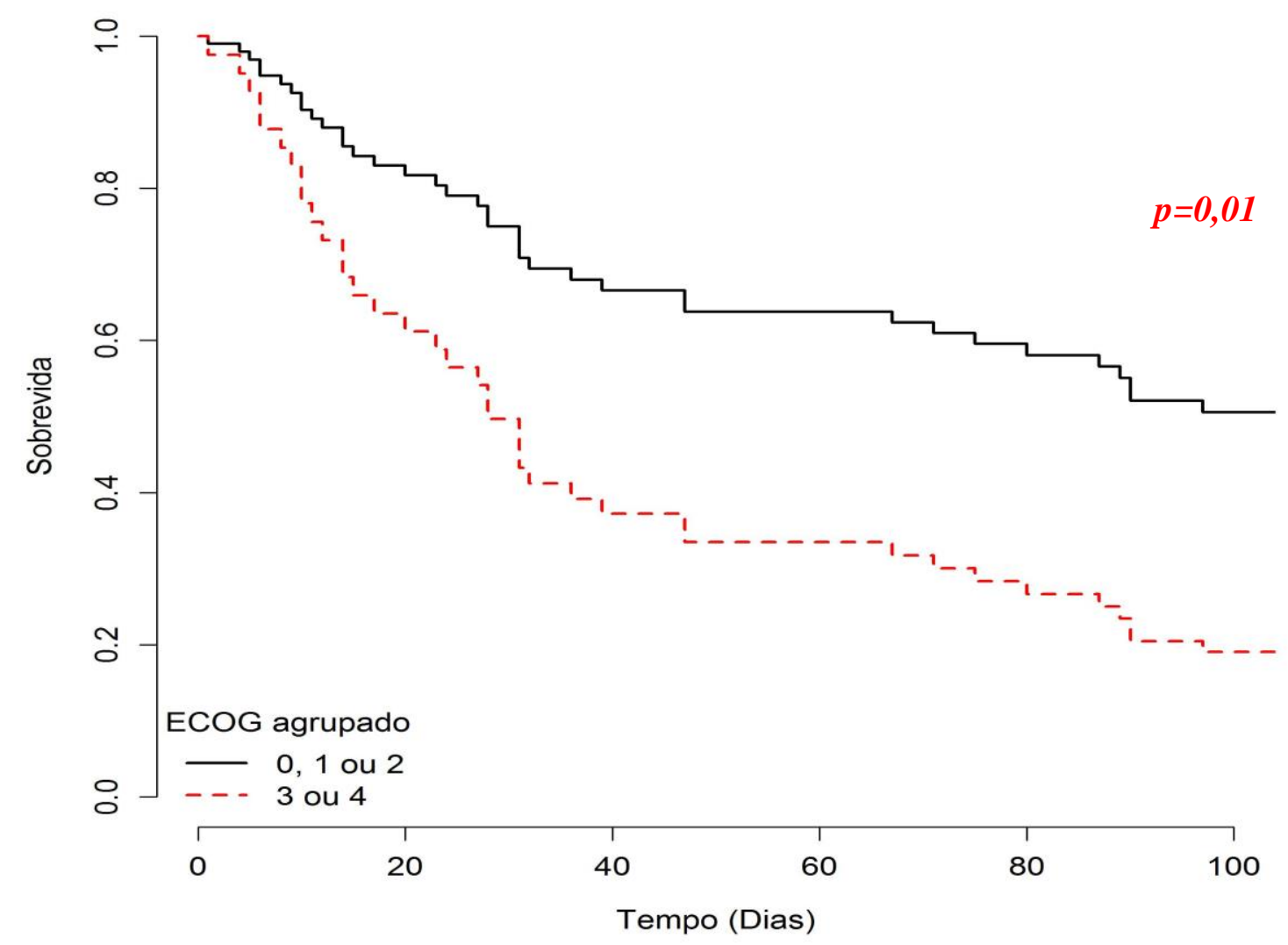

GRÁFICO 7: SOBREVIDA QUANTO AO ECOG 


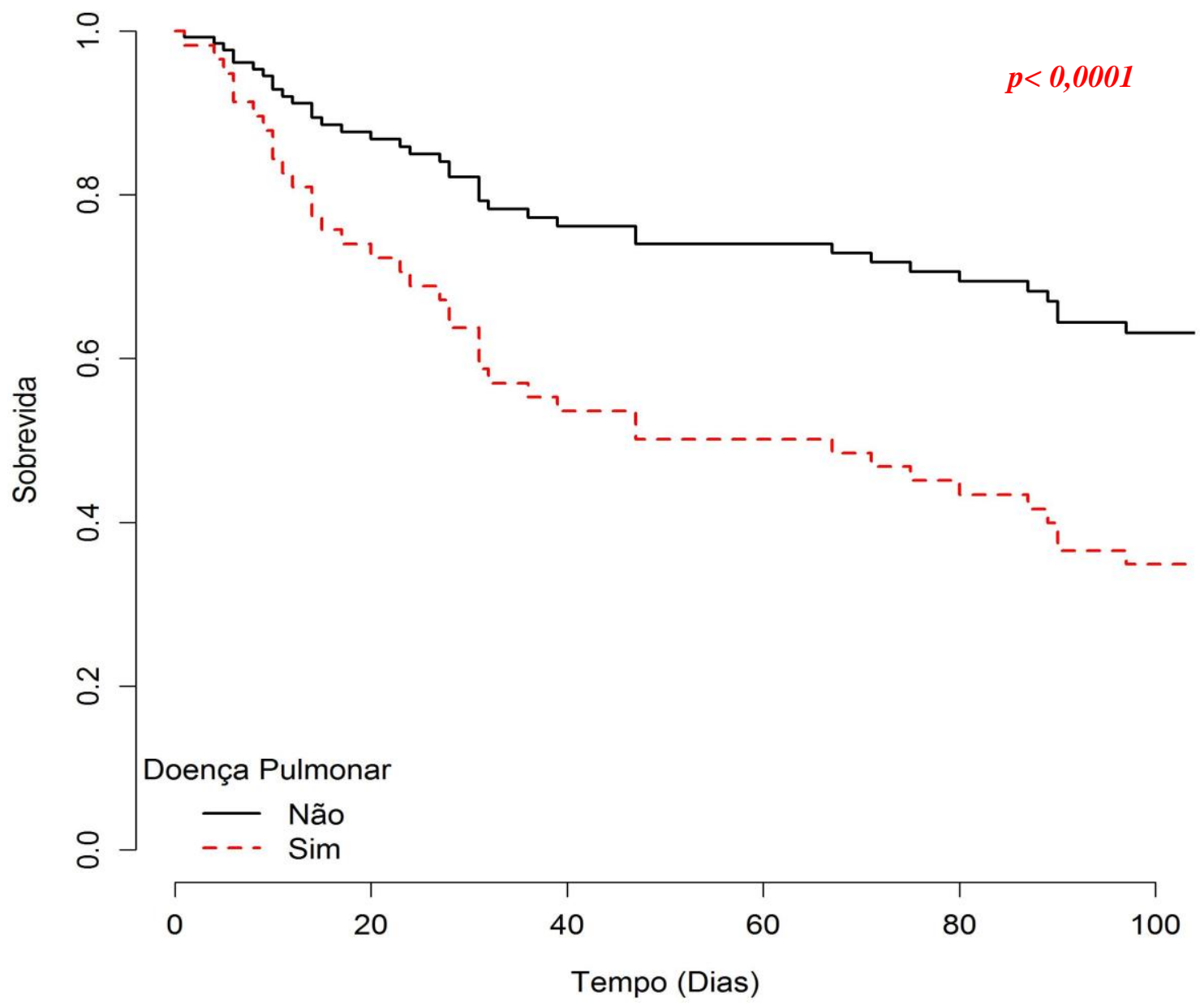

GRÁFICO 8: SOBREVIDA QUANTO À PRESENÇA DE DOENÇA PULMONAR INFECCIOSA EM ATIVIDADE 


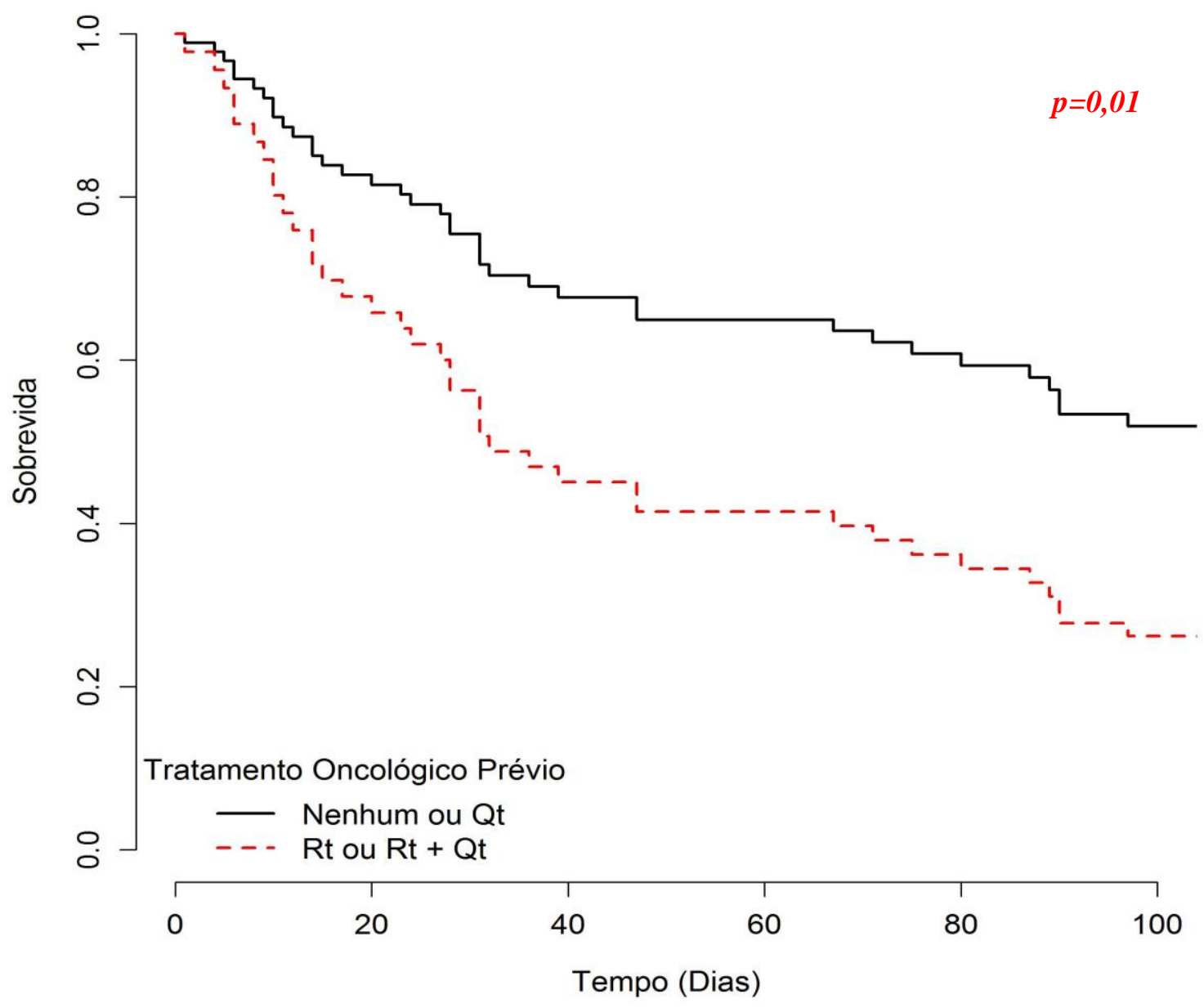

GRÁFICO 9: SOBREVIDA QUANTO AO TIPO DE TRATAMENTO ONCOLÓGICO PRÉVIO

A análise dos dados demográficos e das características clínicas com a sobrevida estão agrupados na Tabela 9. De acordo esta tabela, o risco de óbito é mais que o dobro em pacientes com ECOG 3 e 4 quando comparados aos pacientes com ECOG 0, 1 e 2 (IC 95\% 1,34-4,4). O mesmo ocorre entre os pacientes com história prévia de tratamento com radioterapia, associada ou não à quimioterapia, quando comparados aos pacientes sem tratamento oncológico prévio ou apenas submetidos à quimioterapia e em pacientes com abscesso ou broncopneumonia no momento da passagem da PMAE se comparados à pacientes sem doença pulmonar infecciosa (IC 95\% 1,29-4,06). 
TABELA 9: ANÁLISE DOS DADOS DEMOGRÁFICOS E PARÂMETROS CLÍNICOS DOS PACIENTES QUANTO À SOBREVIDA

\begin{tabular}{|c|c|c|c|}
\hline Variável & $\mathbf{R R}$ & IC $95 \%$ & $p$ \\
\hline \multicolumn{4}{|l|}{ Idade } \\
\hline$<60$ anos & 1 & - & - \\
\hline$\geq 60$ anos & 1,06 & $0,64-1,76$ & 0,82 \\
\hline \multicolumn{4}{|l|}{ Sexo } \\
\hline Feminino & 1 & - & - \\
\hline Masculino & 0,84 & $0,45-1,56$ & 0,57 \\
\hline \multicolumn{4}{|l|}{ ECOG } \\
\hline 0,1 e 2 & 1 & - & - \\
\hline 3 e 4 & 2,43 & $1,34-4,4$ & $<0,0001$ \\
\hline \multicolumn{4}{|l|}{ Albumina Sérica } \\
\hline Normal e Depleção Leve & 1 & - & - \\
\hline Depleção Moderada e Intensa & 1,5 & $0,9-2,51$ & 0,12 \\
\hline \multicolumn{4}{|l|}{ Desenvolvimento da Fístula } \\
\hline Ao diagnóstico do tumor & 1 & - & - \\
\hline Durante o tratamento do tumor & 1,38 & $0,82-2,32$ & 0,22 \\
\hline \multicolumn{4}{|l|}{ Tratamento Oncológico } \\
\hline Nenhum/Quimioterapia & 1 & - & - \\
\hline Radioterapia/Radioterapia+Quimioterapia & 2,04 & $1,15-3,63$ & 0,01 \\
\hline \multicolumn{4}{|l|}{ Doença Pulmonar } \\
\hline Ausente & 1 & - & - \\
\hline $\mathrm{BCP} / A b s c e s s o$ & 2,29 & $1,29-4,06$ & $<0,0001$ \\
\hline
\end{tabular}




\subsubsection{Análise dos parâmetros endoscópicos e radiológicos quanto à sobrevida}

Após análises uni e multivariada por meio da regressão de Cox, a localização da fístula e o diâmetro da mesma não apresentaram impacto na sobrevida dos pacientes.

As correlações entre os parâmetros endoscópicos e radiológicos e a sobrevida estão agrupados na Tabela 10.

TABELA 10: ANÁLISE DOS PARÂMETROS ENDOSCÓPICOS E RADIOLÓGICOS DOS PACIENTES QUANTO À SOBREVIDA

\begin{tabular}{cccc}
\hline \multicolumn{1}{c}{ Variável } & RR & IC 95\% & $\boldsymbol{p}$ \\
\hline Localização da Fístula & 1 & - & - \\
Pleuropulmonar & 0,79 & $0,44-1,4$ & 0,41 \\
Traqueobônquica & & & \\
Diâmetro da Fístula & 1 & - & - \\
$<1 \mathrm{~cm}$ & 1,23 & $0,74-2,04$ & 0,43 \\
\hline $1 \mathrm{~cm}$ &
\end{tabular}




\subsection{Análise dos eventos adversos}

A taxa total de eventos adversos foi de $30 \%$, sendo que a taxa de eventos adversos precoces foi de $2,9 \%(n=2)$ e a de eventos adversos tardios de $27,1 \%(n=19)$.

\subsubsection{Eventos adversos precoces}

Houve um caso $(1,4 \%)$ de insuficiência respiratória aguda por compressão das vias aéreas logo nas primeiras horas após o procedimento, sendo o paciente submetido à colocação de prótese traqueal, com melhora do quadro.

Em outro paciente $(1,4 \%)$, houve perfuração esofágica durante procedimento de dilatação para a passagem da PMAE. O local da perfuração foi completamente ocluído pela própria prótese e não houve outras intercorrências.

\subsubsection{Eventos adversos tardios}

O evento adverso tardio mais frequente foi a migração da prótese, observada em sete pacientes $(10 \%)$. Destes, um paciente era portador de megaesôfago e a prótese foi reposicionada por endoscopia e fixada externamente pela técnica de Shim, isto é, através de fio de fixação externa; três pacientes tiveram a prótese removida e foram submetidos à passagem de nova PMAE; os outros três pacientes já se encontravam em fase terminal da doença e foram submetidos à passagem de sonda nasoenteral.

A obstrução da prótese por crescimento tumoral nas extremidades da mesma foi a segundo evento adverso tardio mais frequente, em cinco pacientes $(7,1 \%)$. Todos os casos ocorreram após 90 dias da passagem da prótese e foram tratados por dilatação e coagulação com plasma de argônio.

Houve três casos $(4,3 \%)$ de hemorragia digestiva alta por rotura de grande vaso. Os pacientes apresentaram hematêmese volumosa, instabilidade hemodinâmica e evoluíram para óbito no mesmo dia. 
Fístulas nas extremidades das próteses ocorreram em dois pacientes $(2,8 \%)$ e foram resolvidas com a colocação de nova PMAE. Também ocorreram dois episódios de obstrução da prótese por impactação alimentar $(2,8 \%)$, que foram resolvidos através de remoção endoscópica.

Os eventos adversos precoces e tardios ocorridos estão na Tabela 11.

TABELA 11: EVENTOS ADVERSOS PRECOCES E TARDIOS OBSERVADOS

Eventos adversos

$\mathbf{n}=\mathbf{2 1}(\%)$

\section{Precoces}

Insuficiência respiratória

$1(1,4)$

Perfuração esofágica

$1(1,4)$

\section{Tardios}

Migração

Crescimento tumoral nas extremidades da prótese

$5(7,1)$

Hematêmese

$3(4,3)$

Fístula

$2(2,8)$

Impactação alimentar
$2(2,8)$ 


\section{DISCUSSÃO}

O câncer de esôfago complicado por FER leva à rápida deterioração do estado geral do paciente, seguida de morte num curto período de tempo, secundária às infecções respiratórias e à má nutrição. Não existem muitas opções terapêuticas disponíveis para o manejo da fístula maligna, haja vista a inoperabilidade da quase totalidade dos pacientes, sendo a prótese metálica autoexpansível método amplamente empregado nesses casos. No entanto, reconhece-se que existem eventos adversos relacionados ao método e, mais importante que isso, observa-se que parcela significativa dos pacientes que são submetidos à passagem da PMAE evoluem de forma desfavorável, com piora súbita do quadro clínico e pulmonar.

Exposto isto, o ideal seria haver uma base mais racional na qual se possa identificar quais pacientes se beneficiariam da utilização da prótese e quais não teriam benefício ou até mesmo teriam piora clínica com o tratamento. Se isso for possível, outros métodos paliativos poderiam ser indicados, evitando procedimento algo invasivo e oneroso ao sistema de saúde. É evidente a escassez de estudos que se dedicaram à essa questão e não se sabe qual a vantagem da prótese na sobrevida do paciente. A maioria das publicações são pequenos estudos de coorte, com curto tempo de seguimento e índices variáveis de sucesso e complicações.

Este estudo analisou, de forma retrospectiva, fatores clínicos, radiológicos e endoscópicos preditivos de insucesso clínico do tratamento paliativo da fístula esofagorespiratória maligna com prótese metálica autoexpansível em pacientes com neoplasia esofágica avançada. Secundariamente também foram estudados fatores que impactaram negativamente a sobrevida desses pacientes, bem como eventos adversos decorrentes da prótese e a evolução do grau de disfagia após o tratamento.

Observou-se alto índice de sucesso técnico na colocação da prótese no local previamente planejado $(98,6 \%)$, com apenas um caso de impossibilidade de passagem da prótese em decorrência de lesão esofágica intransponível ao fio guia. Ao contrário do que se imaginava, houve também elevada taxa de insucesso clínico após a inserção da prótese. Em 44,3\% dos casos não houve benefício clínico real com o tratamento instituído. 
Entre as variáveis analisadas, idade, sexo, nível de albumina sérica, tratamentos oncológicos prévios, doença pulmonar infecciosa em atividade ou localização da fístula nos diversos segmentos da árvore respiratória não foram fatores preditivos para o insucesso clínico. Por outro lado, ECOG 3 e 4, desenvolvimento da fístula durante o tratamento da neoplasia e diâmetro da fístula igual ou superior à $1 \mathrm{~cm}$ foram fatores preditivos para o insucesso clínico. Pacientes com ECOG 3 e 4 apresentaram 8 vezes mais chance de insucesso com o tratamento quando comparados à pacientes com ECOG 0, 1 e 2. Indivíduos que desenvolveram fístula mais tardiamente, durante o tratamento do câncer de esôfago, apresentaram 2,7 vezes mais chance de insucesso do que aqueles que já possuíam a fístula ao diagnóstico da neoplasia. Por fim, portadores de fístula de maior diâmetro apresentaram 3 vezes mais chance de insucesso, se comparados com aqueles cuja fístula era menor que $1 \mathrm{~cm}$ de diâmetro.

A sobrevida média global dos pacientes foi de 111,3 dias. Porém quando analisando separadamente os pacientes com e sem sucesso clínico, a sobrevida média foi de 179 dias para os pacientes que tiveram sucesso clínico e de apenas 25,4 dias nos pacientes que tiveram insucesso clínico, significativamente menor.

Entre as variáveis estudadas, idade, sexo, nível sérico de albumina, localização da fístula nos diversos segmentos da árvore respiratória ou o diâmetro da mesma não impactaram a sobrevida dos pacientes. Contudo, houve relação entre o ECOG, tratamentos oncológicos prévios e doença pulmonar infecciosa em atividade no momento da passagem da prótese com a sobrevida. Após análise estatística, ECOG 3 e 4, tratamento oncológico prévio com radioterapia isolada ou associada à quimioterapia e doença pulmonar infecciosa impactaram negativamente a sobrevida dos pacientes. Observou-se que o risco de óbito foi o dobro nos pacientes com qualquer uma dessas variáveis descritas.

Nossos resultados assemelham-se ao estudo de Shin et $a l .{ }^{45}$, que analisaram os resultados a longo prazo em 61 pacientes com FER paliados com PMAE, obtendo $100 \%$ de sucesso técnico na colocação da prótese no local planejado. O sucesso clínico inicial foi definido como fechamento completo da fístula sete dias após o procedimento, com resolução dos sintomas aspirativos, e foi de $80 \%$. No entanto, $35 \%$ dos pacientes com sucesso clínico inicial evoluíram com reabertura da fístula durante seguimento médio de 4,8 semanas, com recorrência dos sintomas. Houve diferença significativa na sobrevida dos 
pacientes com sucesso e insucesso clínico inicial $(15,1$ semanas $v s 6,2$ semanas, $p<0,05) \mathrm{e}$ o risco de morte foi três vezes maior neste último grupo.

No entanto, outros estudos menores também avaliaram os resultados da utilização da PMAE na oclusão da FER com taxas variadas de sucesso clínico e sobrevida. Turkyilmaz et al. $^{25}$, analisaram resultados da PMAE em 14 pacientes com FER. Eles obtiveram $100 \%$ de sucesso técnico para inserção da prótese e não relataram complicações imediatas ou tardias. A sobrevida média foi de 11,2 semanas (1- 49 semanas), havendo melhora dos sintomas aspirativos em todos os casos. Kim et al. ${ }^{36}$ estudaram os resultados do tratamento paliativo da fístula esofagopulmonar maligna com PMAE em 14 pacientes. Obtiveram $100 \%$ de sucesso técnico e $86 \%$ de sucesso na oclusão da fístula com resolução dos sintomas aspirativos. Houve melhora da disfagia após 7 dias do procedimento e a sobrevida média foi de 101 dias. Todos os pacientes morreram durante o segmento, 13 deles por pneumonia aspirativa.

Alguns estudos compararam os resultados da PMAE com outros métodos paliativos. Chen et al. ${ }^{9}$, analisaram 65 pacientes com carcinoma espinocelular de esôfago e FER, 30 deles tratados com PMAE e 35 com gastro ou jejunostomia. Concluíram que o uso da PMAE foi fator preditivo para uma maior sobrevida $(p=0,026)$, devendo ser considerada primeira linha de tratamento da fístula maligna. Observaram ainda que pacientes submetidos à passagem da prótese foram mais suscetíveis a receber quimioterapia após a oclusão da fístula, o que indicaria melhor controle da infecção respiratória. No entanto, em analise retrospectiva de 35 pacientes com FER malignas, $\mathrm{Hu}$ et al. ${ }^{31}$, concluíram que, apesar de pacientes com PMAE terem sobrevida maior, não houve diferença significativa na sobrevida entre pacientes tratados com PMAE, gastrostomia ou apenas suporte clínico.

A elevada taxa de insucesso clínico observada neste estudo sugere que provavelmente muitos pacientes submetidos à passagem da PMAE já se encontravam bastante debilitados clinicamente, em estágio terminal da doença e desta forma não se beneficiaram do procedimento, o que refletiu diretamente na sobrevida média desses doentes, que foi inferior a um mês. Ao contrário dos estudos anteriores, em nosso trabalho identificamos, de maneira inédita, fatores preditivos do insucesso cínico. É razoável pensar que nos pacientes com ECOG 3 e 4, com fístulas que se desenvolveram mais tardiamente, 
durante o tratamento da neoplasia ou com fístulas de maior diâmetro, a PMAE deve dar lugar a outros métodos paliativos menos invasivos, ou pelo menos postergada até que se consiga uma melhora clínica desses doentes. Acreditamos que, entre as variáveis anteriormente descritas, o ECOG seja a mais importante para determinar o desfecho do tratamento, pois foi o melhor fator preditivo do insucesso e impactou significativamente a sobrevida. Infelizmente as outras duas variáveis apontadas como preditoras do insucesso clínico, que são o diâmetro da fístula e o desenvolvimento mais tardio da mesma em relação ao diagnóstico da neoplasia, não são passíveis de modificação e refletem provavelmente estádio mais avançado da doença neoplásica. O status nutricional, refletido indiretamente no estudo pela albumina sérica, apesar de ter se relacionado ao insucesso clínico apenas na análise univariada, é fator que deve ser levado em consideração para se alcançar melhor desfecho clínico após a prótese e deve, sempre que possível, ser melhorado previamente ao tratamento.

Outro tópico importante apontado pelo estudo foi a presença de doença pulmonar infecciosa ativa impactando negativamente a sobrevida dos pacientes. Acreditamos que deva haver um bom controle da infecção respiratória antes e após a passagem da PMAE, através da instituição de antibioticoterapia ampla e drenagem de abscessos pulmonares.

Quanto aos eventos adversos, a taxa total observada foi de $30 \%$, sendo que a maior parte destes ocorreram tardiamente, ou seja, após 7 dias do procedimento. Os eventos adversos mais frequentes foram a migração $(10 \%)$, a obstrução da prótese por crescimento tumoral nas suas extremidades $(7,1 \%)$ e a hematêmese $(4,3 \%)$. Essa taxa de eventos adversos apesar de elevada, está compatível com os dados encontrados na literatura. Ross et $\mathrm{al}^{35}$, relataram $37 \%$ de eventos adversos maiores, sendo os mais frequentes a hematêmese e o crescimento tumoral das extremidades da prótese. Ainda no estudo de Shin et al. ${ }^{45}$, a taxa de eventos adversos observada foi de $43 \%$, e os mais frequentes, excluindo dor torácica, foram hematêmese $(11 \%)$ e impactação alimentar $(8 \%)$.

O caráter nem sempre estenosante e circunferencial das lesões esofágicas pode ter contribuído para que a migração tenha sido o evento adverso mais frequente no nosso estudo. Por outro lado, alguns pacientes também foram submetidos a tratamentos oncológicos com a quimioterapia e a radioterapia após o procedimento, favorecendo a redução do tamanho da lesão e o deslocamento da prótese. Já a obstrução da prótese por 
crescimento tumoral nas suas extremidades ocorreu apenas em pacientes com sobrevida superior a 90 dias e, em todos os casos, foi tratado por via endoscópica, sem maiores dificuldades.

Houve melhora significativa na disfagia referida pelo paciente após a inserção da prótese, o que provavelmente levou à melhora na qualidade de vida dos doentes, embora esta variável não tenha sido avaliada. Anteriormente ao tratamento, o grau médio de disfagia era de 3,86 e, quinze dias após o procedimento, de 2,32 ( $p<0,001)$.

O presente estudo apresenta limitações que requerem comentários adicionais. Tratase de estudo retrospectivo e, mesmo tendo sido realizado através da análise de banco de dados elaborado de forma prospectiva, nem todos os pacientes puderam ser incluídos devido à registros incompletos. Também não foi possível uniformizar a escolha das próteses inseridas. Foram utilizadas próteses de marcas variadas, sendo a opção muitas vezes baseada na disponibilidade da mesma no serviço. Outra limitação se refere à realização do estudo em centro universitário de referência, dedicado exclusivamente ao tratamento do câncer, o que restringe a validação externa dos resultados aqui obtidos.

Vale, por fim, ressaltar a contribuição do presente estudo em identificar fatores preditivos relacionados ao insucesso clínico, evitando acrescentar mais morbidade à pacientes já debilitados por uma doença agressiva como o câncer esofágico. Sabemos que nestes doentes, a paliação é de suma importância, mas até o momento não existe terapia ideal, e esta deve ser individualizada, respeitando as características pessoais e a vontade de cada paciente e seus familiares. 


\section{CONCLUSÃO}

A análise dos resultados permitiu as seguintes conclusões:

ECOG 3 e 4, desenvolvimento da fístula durante o tratamento do câncer esofágico e diâmetro da fístula igual ou superior a $1 \mathrm{~cm}$ são fatores preditivos de insucesso clínico do tratamento das fístulas esofagorrespiratórias com prótese metálica autoexpansível em pacientes com câncer esofágico.

ECOG 3 e 4, tratamento oncológico prévio com radioterapia, isolada ou associada à quimioterapia e doença pulmonar infecciosa em atividade no momento da passagem da prótese foram fatores que impactaram negativamente a sobrevida dos pacientes.

Houve melhora significativa no grau de disfagia referido pelos pacientes após a inserção da prótese.

A ocorrência de eventos adversos foi elevada. Os mais observados foram a migração da prótese e a obstrução da mesma por crescimento tumoral nas suas extremidades, tratadas com sucesso pela via endoscópica. 


\section{REFERÊNCIAS}

1. Thrift AP. The epidemic of oesophageal carcinoma: Where are we now? Cancer Epidemiol. 2016;41:88-95.

2. American Cancer Society.Cancer Statistics Center. 2016 Estimates.

3. Instituto Nacional do Câncer. Ministério da Saúde. Instituto Nacional do Câncer. Estimativas 2014: Incidência do Câncer no Brasil. Rio de Janeiro (INCA).

4. Zhang Y. Epidemiology of esophageal cancer. World J Gastroenterol. 2013;19(34):5598.

5. Bjerring OS, Pless T, Fristrup C MM. Acceptable results after self-expanding metallic stent treatment for dysphagia in non-resectable oesophageal cancer. Dan Med J. 2012;59(6).

6. Bustamante FAC, Hourneaux de Moura EG, Bernardo W, Sallum RAA, Ede E, Baba E. Surgery versus endoscopic therapies for early cancer and high-grade dysplasia in the esophagus: a systematic review. Arq Gastroenterol. 2016;53(1):10-19.

7. Dobrucali A, Caglar E. Word Journal of Gastroenterology. World J Gastroenterol. 2010;16(45):5739-5745.

8. Madhusudhan C, Saluja SS, Pal S, et al. Palliative stenting for relief of dysphagia in patients with inoperable esophageal cancer: impact on quality of life. Dis Esophagus. 2009;22(4):331-336.

9. Chen M, Yang Y, Lai C. Outcome of patients with esophageal cancer: a nationwide analysis. Ann Surg Oncol. 2013;20(9).

10. Im JP, Kang JM, Kim SG, Kim JS, Jung HC, Song IS. Clinical Outcomes and Patency of Self-expanding Metal Stents in Patients with Malignant Upper Gastrointestinal Obstruction. Dig Dis Sci. 2008;53(4):938-945.

11. Kim JY, Kim SG, Lim JH, Im JP, Kim JS, Jung HC. Clinical outcomes of esophageal stents in patients with malignant esophageal obstruction according to palliative additional treatment. J Dig Dis. 2015;16(10):575-584.

12. Hourneaux G, de Moura E, Sakai P, Cecconello I, Ishioka S. [Palliative treatment of advanced esophageal cancer. Comparative study: auto-expandable metal stent and isoperistaltic esophagogastric bypass]. Acta Gastroenterol Latinoam. 2001;31(1):13-22.

13. Shin J, Song H, Ko G, Lim J, Yoon H, Sung K. Esophagorespiratory Fistula: Long-term Results of Palliative Treatment with Covered Expandable Metallic Stents in 61 Patients. Radiology. 2004;232:252-259. 
14. Hürtgen M, Herber SC a. Treatment of malignant tracheoesophageal fistula. Thorac Surg Clin. 2014;24(1):117-127.

15. Choi MK, Park YH, Hong JY, et al. Clinical implications of esophagorespiratory fistulae in patients with esophageal squamous cell carcinoma (SCCA). Med Oncol. 2010;27(4):12341238.

16. Shin JH, Kim J-H, Song H-Y. Interventional management of esophagorespiratory fistula. Korean J Radiol. 2010;11(2):133-140.

17. Lee KE, Shin JH, Song HY, Kim SB, Kim KR, Kim JH. Management of airway involvement of oesophageal cancer using covered retrievable nitinol stents. Clin Radiol. 2009;64(2):133-141.

18. Murthy S, Gonzalez-Stawinski G V., Rozas MS, Gildea TR, Dumot JA. Palliation of malignant aerodigestive fistulae with self-expanding metallic stents. Dis Esophagus. 2007;20(5):386-389.

19. Balazs A, Kupcsulik PK, Galambos Z. Esophagorespiratory fistulas of tumorous origin. Non-operative management of 264 cases in a 20-year period. Eur J Cardio-Thoracic Surg. 2008;34(5):1103-1107.

20. Alexander EP, Trachiotis GD, Lipman TO, Wadleigh RG. Evolving management and outcome of esophageal cancer with airway involvement. Ann Thorac Surg. 2001;71(5):1640-1644.

21. Dai Y, Chopra SS, Kneif S, Hünerbein M. Management of esophageal anastomotic leaks, perforations, and fistulae with self-expanding plastic stents. J Thorac Cardiovasc Surg. 2011;141:1213-1217.

22. Rodriguez AN, Diaz-Jimenez JP. Malignant respiratory-digestive fistulas. Curr Opin Pulm Med. 2010;16(4):329-333.

23. Davydov M, Stilidi I, Bokhyan V, Arzykulov G. Surgical treatment of esophageal carcinoma complicated by fistulas. Eur J Cardio-Thoracic Surg. 2001;20(2):405-408.

24. Domene CE, Cecconello I, Zilberstein B, Ishioka S, Sakai P PH. Esophageal Intubation for tracheo-esophageal fistula. Rev Col Bras Cir. 1999;26(2):91-95.

25. Turkyilmaz A, Aydin Y, Eroglu A, Bilen Y, Karaoglanoglu N. Palliative management of esophagorespiratory fistula in esophageal malignancy. Surg Laparosc Endosc Percutan Tech. 2009;19(5):364-367.

26. Domschke W, Foerster EC, Matek W RW. Self-expanding mesh stent for esophageal cancer stenosis. Endoscopy. 1990;22(3):134-136. 
27. Wallace M, Lauwers G, Chen Y, et al. Miami classification for probe-based confocal laser endomicroscopy. Endoscopy. 2011;43(10):882-891.

28. Langer FB, Zacherl J. Palliative endoscopic interventions in esophageal cancer. Eur Surg. 2007;39(5):288-294.

29. Siersema PD, Schrauwen SL, van Blankenstein M, et al. Self-expanding metal stents for complicated and recurrent esophagogastric cancer. Gastrointest Endosc. 2001;54(5):579586.

30. Evans JA, Early DS, Chandraskhara V, et al. The role of endoscopy in the assessment and treatment of esophageal cancer. Gastrointest Endosc. 2013;77(3):328-334.

31. Hu Y, Zhao YF, Chen LQ, et al. Comparative study of different treatments for malignant tracheoesophageal/bronchoesophageal fistulae. Dis Esophagus. 2009;22(6):526-531.

32. Shin JH, Song H-Y, Ko G-Y, Lim J-O, Yoon H-K, Sung K-B. Esophagorespiratory Fistula: Long-term Results of Palliative Treatment with Covered Expandable Metallic Stents in 61 Patients. Radiology. 2004;232(1):252-259.

33. Herth FJF, Peter S, Baty F, Eberhardt R, Leuppi JD, Chhajed PN. Combined airway and oesophageal stenting in malignant airway-oesophageal fistulas: a prospective study. Eur Respir J. 2010;36(6):1370-1374.

34. Chen Y-H, Li S-H, Chiu Y-C, et al. Comparative Study of Esophageal Stent and Feeding Gastrostomy/Jejunostomy for Tracheoesophageal Fistula Caused by Esophageal Squamous Cell Carcinoma. Moon C, ed. PLoS One. 2012;7(8):e42766.

35. Ross WA, Alkassab F, Lynch PM, et al. Evolving role of self-expanding metal stents in the treatment of malignant dysphagia and fistulas. Gastrointest Endosc. 2007;65(1):70-76.

36. Kim KR, Shin JH, Song H-Y, et al. Palliative Treatment of Malignant Esophagopulmonary Fistulas With Covered Expandable Metallic Stents. Am J Roentgenol. 2009;193(4):W278W282.

37. Schoppmann SF, Langer FB, Prager G, Zacherl J. Outcome and complications of long-term self-expanding esophageal stenting. Dis Esophagus. 2013;26(2):154-158.

38. Sarper A, Oz N, Cihangir C, Demircan A, Isin E. The efficacy of self-expanding metal stents for palliation of malignant esophageal strictures and fistulas 2 . Eur J CardioThoracic Surg. 2003;23(5):794-798.

39. May A, Ell C. Palliative Treatment of Malignant Esophagorespiratory Fistulas With Gianturco-Z Stents: A Prospective Clinical Trial and Review of the Literature on Covered Metal Stents. Am J Gastroenterol. 1998;93(4):532-535. 
40. Silon B, Siddiqui AA, Taylor LJ, Arastu S, Soomro A, Adler DG. Endoscopic Management of Esophagorespiratory Fistulas: A Multicenter Retrospective Study of Techniques and Outcomes. Dig Dis Sci. 2017;62(2):424-431.

41. Litchford M. Advanced Practitioner's Guide to Nutrition and Wounds.3rd. 3rd ed. CASE Software \& Books; 2010.

42. Oken MM, Creech RH, Tormey DC, et al. Toxicity and response criteria of the Eastern Cooperative Oncology Group. Am J Clin Oncol. 1982;5(6):649-655.

43. Mellow MH, Pinkas H. Endoscopic laser therapy for malignancies affecting the esophagus and gastroesophageal junction. Analysis of technical and functional efficacy. Arch Intern Med. 1985;145(8):1443-1446.

44. Baron TH. Minimizing Endoscopic Complications: Endoluminal Stents. Gastrointest Endosc Clin N Am. 2007;17(1):83-104.

45. Shin JH, Song H-Y, Ko G-Y, Lim J-O, Yoon H-K, Sung K-B. Esophagorespiratory fistula: long-term results of palliative treatment with covered expandable metallic stents in 61 patients. Radiology. 2004;232(1):252-259. 